\title{
Experienced Meditators, Cancer Survivors, and Matched Controls Assemble Different Neural Resources to Process Emotion
}

\author{
Susan Bauer-Wu ${ }^{1}$ \\ Andrew J. Butler ${ }^{2}$ \\ Justin K. Rajendra ${ }^{3}$ \\ Rachael Whitworth ${ }^{4}$ \\ Giuseppe Pagnoni ${ }^{5}$ \\ Wendy Hasenkamp 1,6 \\ Christine D. Wilson-Mendenhall ${ }^{7}$ \\ Lauren A. M. Lebois ${ }^{8}$ \\ Jonathan H. Drucker ${ }^{9}$ \\ W. Kyle Simmons ${ }^{10,11}$ \\ John D. Dunne ${ }^{7}$ \\ Brendan Ozawa-de Silva ${ }^{12}$ \\ Lisa Feldman Barrett ${ }^{13,14}$ \\ Lawrence W. Barsalou ${ }^{15}$ \\ ${ }^{1}$ Mind \& Life Institute \\ ${ }^{2}$ Georgia State University \\ ${ }^{3}$ National Institutes of Mental Health \\ ${ }^{4}$ Newport, RI \\ ${ }^{5}$ University of Modena and Reggio Emilia \\ ${ }^{6}$ University of Virginia \\ ${ }^{7}$ University of Wisconsin-Madison \\ ${ }^{8}$ McLean Hospital / Harvard Medical School \\ ${ }^{9}$ Brain Vision \\ ${ }^{10}$ The Laureate Institute for Brain Research \\ ${ }^{11}$ Faculty of Community Medicine, University of Tulsa \\ ${ }^{12}$ Life University \\ ${ }^{13}$ Northeastern University \\ ${ }^{14}$ Massachusetts General Hospital / Harvard Medical School \\ ${ }^{15}$ University of Glasgow
}

25 July 2017

Running title: Population Differences in Emotion

\section{Address correspondence to:}

Lawrence W. Barsalou

Department of Psychology

University of Glasgow

58 Hillhead Street

Glasgow G12 8QB, Scotland

+01413303035

Lawrence.Barsalou@glasgow.ac.uk 


\begin{abstract}
According to constructivist theories of emotion, members of different populations experience emotion differently as a result of assembling different neural resources to produce it. To test this prediction, we sampled individuals from three populations (experienced meditators, cancer survivors, matched controls) and used functional magnetic resonance imaging (fMRI) to assess their neural responses to four kinds of affective phrases (positive cancer, negative cancer, positive non-cancer, negative noncancer). As predicted, the three populations responded differently to these affective phrases. When assessing neural activity for positive vs. negative phrases, controls showed the standard negativity bias reported in the emotion literature, cancer survivors showed a positivity bias (perhaps related to personal growth following cancer), and experienced meditators showed no bias (perhaps reflecting the mental quality of equanimity established through regular meditation practice). When assessing neural activity for positively-valenced cancer vs. non-cancer phrases, controls exhibited difficulty engaging with the cancer phrases, engaging much more with the non-cancer phrases instead. In contrast, experienced meditators and cancer survivors engaged more with the cancer phrases, while exhibiting different affective styles. Together these results indicate that experienced meditators, cancer survivors, and matched controls assemble different neural resources to process emotion.
\end{abstract}

Keywords: emotion, constructivist theory, grounded cognition, meditators, cancer patients 
According to constructivist theories of emotion, an emotional state results from assembling perceptual, cognitive, interoceptive, and motor resources relevant for comprehending an emotional situation and coping with it effectively (Barrett, 2006a, 2006b; Gendron \& Feldman Barrett, 2009; Wilson-Mendenhall, Barrett, Simmons, \& Barsalou, 2011). To see how this account works, imagine that a distressed man enters your workplace, and begins firing a gun wildly in the air. According to constructivist theories, perceptual processes enable you to recognize that a distressed person and a gun are present; cognitive processes indicate that you and others are threatened, anticipating the potential implications; your body might become aroused to the point of panic, with your heart racing and breath catching; your motor system might freeze initially and then prepare to flee. From the constructivist perspective, your brain has activated neural resources that are well suited for understanding and coping with this particular emotional situation. As a result of all these processes becoming active and assembled together coherently, they produce one of many possible states of fear.

Now imagine instead that, on previous occasions, you practiced assembling a different set of neural resources in this type of situation. For example, your employer might have provided you with training on how to coolly handle such situations in your workplace, should they occur. Or perhaps you are an experienced Buddhist meditator, who has practiced producing states of equanimity (remaining balanced and calm in emotionally-charged situations), and who has also practiced feeling empathy and compassion for others, no matter how negative and destructive they might be (e.g., Ricard, 2007; Salzberg, 2002). As a result of such earlier experiences, when a gunman starts firing in your workplace, you might assemble a somewhat atypical set of neural resources to understand and cope with the situation. Rather than experiencing fear and fleeing, you might experience compassion and attempt to reason with the gunman about possibly taking a more positive course of action. Indeed, Antoinette Tuff, a clerk at an elementary school in Decatur, Georgia did just this. After having been trained to handle this kind of situation, she calmly talked a distressed gunman who entered her school into surrendering before he killed anyone, expressing love for him in the process (Margolin, MSNBC, 2013).

According to constructivist theories of emotion, two different affective responses to the same situation result from assembling different perceptual, cognitive, interoceptive, and motor resources for 
processing it. Not only can such differences occur between different individuals, they can also occur within the same individual. Imagine, for example, how the affective experience of everyday life events might change as function of surviving life-threatening cancer. As much research shows, young- to middle-aged adults often exhibit a negativity bias, focusing more on negative events than on positive ones (e.g., Reed \& Carstensen, 2012). Conversely, some (but not all) cancer survivors often become more positive about life after receiving a second chance (Bower et al., 2005; Jim \& Jacobsen, 2008). Prior to having cancer, these particular cancer patients might be more oriented to the negative emotion of losing a job than to the positive emotion of enjoying a sunset. After surviving cancer, however, they might focus more on positive life experiences, no matter how minor, and be less concerned about losses and failures, even when major.

According to constructivist theories, such shifts in emotional orientation result from learning to assemble different neural resources when encountering emotional situations. In negative situations, individuals might become more likely to activate neural resources that construe negative events in constructive ways, producing personal growth (Park, Chmielewski, \& Blank, 2010). Similarly, in positive situations, individuals might become more likely to activate resources that affirm the good side of human nature, producing inspiration to act selflessly and generously (Fredrickson, 2001).

Thus, our aim in the study reported here was to test an a priori prediction that follows from the constructivist perspective: If emotion results from assembling relevant resources for effectively understanding and coping with an emotional situation, then the relevant resources for producing emotion should vary across populations. Because different populations often adopt different perspectives on the same emotional situation, they should assemble different neural resources to comprehend, experience, and act effectively in it. To assess this possibility, the study reported here compared the neural activity of experienced meditators, cancer survivors, and matched controls as they processed a common set of emotional phrases. To the extent that the constructivist prediction is correct, different patterns of neural activity should arise across populations, indicating that they draw on different neural resources to process emotion. 


\section{Developing Habitual Patterns of Emotional Processing}

To explain how different populations develop different emotional styles, we develop an account based on the construct of situated conceptualization (Barsalou, Niedenthal, Barbey, \& Ruppert, 2003; Barsalou, 2003, 2009, 2013; Yeh \& Barsalou, 2006). According to this account, multiple processing streams in the brain simultaneously perceive and conceptualize various aspects of a current emotional situation, including the setting, agents, objects, actions, events, mental states, and self-relevance. As these individual elements of the situation are conceptualized, global conceptualizations of the situation integrate these elemental conceptualizations into a coherent interpretation of what is occurring across the situation as a whole (e.g., how an emotional event bears on one's self interests, how various coping actions might regulate the situation and one's bodily responses to it; cf. Lazarus, 2001). Together, these elemental and global conceptualizations are assembled into a situated conceptualization that represents and interprets the situation at multiple levels. To the extent that the situation is conceptualized as having positive or negative implications for oneself, emotional experience may result (Barrett, 2006a, 2006b; Wilson-Mendenhall et al., 2011). From the constructivist perspective, emotion results from conceptualizing a situation in a certain way.

As a situated conceptualization becomes assembled to interpret a situation, it is stored in memory via associative mechanisms. Once stored, it can later be reactivated and adapted when a similar situation is encountered again, or just part of the original situation. Once reactivated, the situated conceptualization reinstates itself in the brain and body, reproducing a state similar to the original emotional experience. Because the reactivated conceptualization is grounded in perceptual, cognitive, interoceptive, and motor systems, it does not simply describe symbolically how the situation is conceptualized, but instead activates perceptions, cognitions, bodily states, and actions associated with the original emotion. To the extent that the reactivated emotion is appropriate for the current situation, it provides useful pattern completion inferences about it. If inappropriate, it may distort experience and behavior in ways that can be counter-productive and potentially dysfunctional or pathological.

The predictions for the study reported here rest on the assumption that the construction, 
storage, and application of situated conceptualizations in emotional situations can vary significantly across populations. To the extent that different populations conceptualize situations differently, they establish different situated conceptualizations of them. Across months and years of emotional experience, large collections of these differing conceptualizations may become increasingly established in memory. As new situations with emotional affordances are encountered, they activate relevant emotional memories that produce effective emotional processing as pattern completion inferences. Because different populations store different collections of situated conceptualizations from prior emotional experience, the resultant emotions that arise from retrieving and applying these memories to current situations varies significantly.

\section{Emotional Processing in Experienced Meditators}

To the extent that the constructivist account of emotion is correct, what kinds of emotional style might experienced meditators exhibit? Increasing research demonstrates that various meditation practices decrease emotional reactivity, not only to negative stimuli but also to positive ones (e.g., Brefczynski-Lewis, Lutz, Schaefer, Levinson, \& Davidson, 2007; Huffziger et al., 2013; Moyer et al., 2011; Taylor et al., 2011). In general, decreased reactivity appears to result from becoming increasingly able to view emotions as transitory mental states, rather than becoming immersed in subjectively experiencing them as real (for a review, see Chambers, Gullone, \& Allen, 2009).

Meditation can also promote pro-social attitudes, especially after performing practices that explicitly develop compassion for others. Increasing research demonstrates that practicing compassion meditation increases a wide variety of behaviors, neural states, and peripheral physiological states associated with pro-sociality and the desire to help others (Condon, Desbordes, Miller, \& DeSteno, 2013; Desbordes et al., 2012; Fredrickson, Cohn, Coffey, Pek, \& Finkel, 2008; Jazaieri et al., 2013; Klimecki, Leiberg, Lamm, \& Singer, 2012; Lutz, Brefczynski-Lewis, Johnstone, \& Davidson, 2008; Lutz, Greischar, Perlman, \& Davidson, 2009; Mascaro, Rilling, Negi, \& Raison, 2013; Pace et al., 2009; Weng et al., 2013). In general, practicing compassion meditation appears to increase interest in others' well-being (for a review, see Hofmann, Grossman, \& Hinton, 2011).

To the extent that meditation practices increase equanimity and pro-sociality, the neural 
resources that meditators recruit to process emotional situations could reflect these mental qualities. Our study here attempted to assess this emotional style in two ways. First, we assessed whether experienced meditators exhibit greater equanimity to both positive and negative phrases, such as "warm hug" and "dishonest spouse," than do matched controls. If so, then meditators should respond less differentially to positive vs. negative phrases than do controls. Second, we assessed whether experienced meditators exhibited greater interest in affective phrases related to cancer, such as "cancer recurrence," than do matched controls. If so, then meditators should be more likely to recruit brain areas related to experiencing cancer empathetically and compassionately.

\section{Emotional Processing in Cancer Survivors}

To the extent that the constructivist account of emotional processing is correct, what emotional styles might cancer survivors exhibit? Given that cancer is a highly embodied experience, it is not surprising that significant emotion is often directed at the body during both treatment and recovery. During treatment, tremendous amounts of negative emotion may be associated with cancer-related pain, bodily disfigurement, threats to life, and other challenges to physical and mental well-being (e.g., Bullen et al., 2012; Given \& Given, 2013; Lo et al., 2010; Sharpe, Patel, \& Clarke, 2011). During recovery, survivors may experience significant dislike for their body, along with doubts about its resilience and effectiveness (e.g., Falk Dahl, Reinertsen, Nesvold, Fosslaa, \& Dahl, 2010; Fobair et al., 2006; Krumwiede \& Krumwiede, 2012). As a consequence, survivors may devote much time and effort to strengthening and developing confidence in their bodies again, to the point of establishing new physical identities as capable athletes (e.g., Dunn, Campbell, Penn, Dwyer, \& Chambers, 2009; Parry, 2008; Sabiston, McDonough, \& Crocker, 2007).

Beyond the body, cancer recovery is often associated with significant personal change and growth, further associated with intense emotion (Jim \& Jacobsen, 2008). After comprehending the very real possibility of death and receiving a second chance at life, cancer survivors often reflect and find meaning in their experience (Bower et al., 2005; Dirksen, 1995; Jim, Purnell, Richardson, Golden-Kreutz, \& Andersen, 2006; Kernan \& Lepore, 2009). Although meaning making can lead to positive insights, it can also lead to negative feelings of vulnerability and blame. As an outcome of 
meaning making, cancer survivors often experience significant changes in identity (e.g., Cordova et al., 2007, 2007; Kashdan \& Kane, 2011; Park, Zlateva, \& Blank, 2009). For example, cancer survivors may experience greater resilience, personal growth, and experiential acceptance; alternatively they may identify as victims, experience post-traumatic stress disorder (PTSD), and become depressed (e.g., Bell, 2012; Bullen et al., 2012; Jim \& Jacobsen, 2008). Finally, meaning making and identity development may produce changes in the quality of life (e.g., Komura \& Hegarty, 2006; Linley \& Joseph, 2004; Mystakidou et al., 2007; Park, Lechner, Antoni, \& Stanton, 2009). Although quality of life can diminish, it often improves, with many cancer survivors experiencing a new appreciation of life and improved interpersonal relationships, generally referred to as "posttraumatic growth" (e.g., Connerty \& Knott, 2013; Park et al., 2010; Tedeschi, Tedeschi, Park, \& Calhoun, 1998).

To the extent that experiencing cancer produces intense emotion related to the body and personal growth, the neural resources that cancer survivors recruit to process emotional situations could reflect this experience. Our study here attempted to assess this emotional style in two ways. First, we assessed whether cancer survivors associate cancer with bodily experience. If so, then when cancer survivors process affective phrases about cancer (e.g., "tufts of hair"), they should be more likely to recruit brain areas associated with bodily experience than do matched controls. Second, and more generally, we assessed whether the topic of cancer continues to produce strong emotional intensity in cancer survivors as a consequence of personal growth. If so, then when cancer survivors process affective phrases about cancer, they should process them more extensively than matched controls, and perhaps exhibit a different affective perspective of some kind.

\section{Overview and Hypotheses}

To assess whether meditation and cancer experience produce different emotional styles, participants were sampled from three populations: experienced meditators, cancer survivors, and matched controls. On each trial during an fMRI scan, participants listened to a phrase and rated their familiarity with it. Across trials, participants listened to 180 phrases having either a positive or negative valence (e.g., kind heart, job loss), randomly intermixed with 90 neutral phrases as fillers 
(e.g., brushing teeth, pair of gloves). For the positive and negative phrases, half were related to cancer (e.g., in remission, disease recurrence), and half were unrelated to cancer (e.g., watching the sunset, bad breath). After hearing each phrase, participants judged its familiarity. Although this task did not require participants to produce emotional responses, we assumed that participants would produce emotional responses implicitly (as demonstrated in much previous literature; e.g., Lench, Flores, \& Bench, 2011). From the constructivist perspective, we further assumed that these implicit responses would result from assembling relevant neural resources used previously when producing emotional responses to similar stimuli.

General hypothesis. If the constructivist perspective is correct, then the neural resources assembled to produce implicit emotional responses should vary systematically across populations, reflecting each population's different situational experience with emotion. Thus, when experienced meditators, cancer survivors, and matched controls produce emotional responses to the same affective phrases implicitly, different neural assemblies should become active across populations. Four specific forms of this general hypothesis follow.

Meditation hypothesis 1. As discussed earlier, meditation practice is often assumed to produce equanimity, causing experienced practitioners to remain calm, impartial, and even-tempered, while richly experiencing both positive and negative events. As a consequence, meditators should produce relatively similar responses to positive and negative phrases, not differentiating between them as much as do control participants (and possibly cancer survivors). Specifically, neural activity to positive and negative phrases should not differ as much for experienced meditators as for the other two groups.

Meditation hypothesis 2. Because meditators are typically exposed to compassionate values and often practice compassion meditation, they should be highly oriented towards the suffering of others, including individuals with cancer and other illnesses. If so, then when meditators receive cancer phrases, they should be likely to exhibit interest, empathy, and compassion, activating relevant neural resources, more so than controls.

Cancer hypothesis 1. Because having cancer is heavily associated with salient physical and 
interoceptive experiences, cancer phrases should activate neural areas associated with bodily experience more for cancer survivors than for matched controls.

Cancer hypothesis 2. Cancer survivors have gone through intense emotional experiences associated with cancer and experienced considerable personal change, often accompanied by personal growth. To the extent that personal growth occurs, cancer phrases should produce implicit responses to affective stimuli that reflect this growth. If, for example, cancer survivors develop a more positive outlook on life, then the neural resources that they assemble to process positive vs. negative affective phrases may differ from those that control participants assemble.

\section{Methods}

\section{Design and Participants}

Two variables - participant group and phrase type - were crossed in a mixed repeatedmeasures design, with phrase type constituting the repeated measure (as described later in Materials). For participant group, three middle-aged groups were sampled from the Emory University (Atlanta, GA) community: 14 experienced meditators (6 women), 9 cancer survivors (5 women), and 14 matched controls (8 women). Three additional participants were dropped from the control group (beyond the 14 included) due to excessive head motion (2) or imaging problems (1). We originally intended to include the same number of cancer survivors as meditators and controls, but many of the cancer survivors recruited did not meet the criteria for undergoing MRI (e.g., they often had metal in their bodies from cancer treatment). Although the time and resources available for performing this experiment did not allow us to recruit further, the 9 cancer survivors scanned produced clear reliable results, as described later.

Regarding eligibility criteria, the cancer survivors were not meditators; the meditators were not cancer survivors; the controls were neither meditators nor cancer survivors (nor had they experienced another serious, life-limiting illness). All cancer survivors had a confirmed major cancer diagnosis, had received systemic treatment with chemotherapy during the past two years, and were currently in remission. Meditators had a regular contemplative practice of at least 20 minutes a day for at least 3 days per week for a minimum of 2 years. These participants estimated that they had practiced a 
median of 1,117 hours (ranging 208 to 4,156 hours), representing a wide variety of meditation practices that included focusing on the breath, focusing on bodily sensations, cultivating compassion, noticing whatever enters consciousness, and monitoring thoughts and emotions. Prior to being scanned, all participants provided informed consent and were screened for any mitigating factors or potential problems that could arise during MRI. Participants received $\$ 50$ compensation.

As Supplemental Table S1 illustrates, the three groups were equated for age, gender, and education, and also for their affective state just prior to the scan. Affective state was assessed in two ways: First, participants rated how happy they were currently on a continuous 1-10 visual analogue scale, and similarly rated how tense they were, with 10 indicating maximum happiness or tenseness. Second, participants completed the expanded version of the Positive and Negative Affect Schedule (PANAS-X; Watson \& Clark, 1999). As can be seen in Table S1, the three groups were experiencing relatively little affect, slightly more positive than negative. The three groups only differed on their current stress experience, as measured with the Calgary Symptoms of Stress Inventory (CSoSI; Carlson \& Thomas, 2007). Although cancer survivors were experiencing greater stress, this did not predispose them to being more negative than the other two groups on either of the individual differences measures just described, nor later in the imaging data.

\section{Materials}

Five groups of phrases were developed initially, with each phrase containing two or three words: 134 positive affect phrases not related to cancer $(\mathrm{NC}+), 136$ negative affect phrases not related to cancer (NC-), 148 positive affect phrases related to cancer $(\mathrm{C}+), 194$ negative affect phrases related to cancer (C-), and 241 neutral phrases, some related to health and others not (Neut). These 853 phrases were given to 8 cancer survivors (not participating in the main imaging experiment), who rated each phrase for affect, familiarity, and cancer relevance on discrete 1-7 scales. For affect, 1 indicated high negative valence, 4 indicated neutral valence, and 7 indicated high positive valence. For familiarity, 1 indicated no familiarity and 7 indicated high familiarity. For cancer relevance, 1 indicated no cancer relevance, 4 indicated equal relevance to cancer and other things, and 7 indicated only relevance for cancer. 
These ratings were then used to construct the sets of $\mathrm{NC}+, \mathrm{NC}-, \mathrm{C}+, \mathrm{C}-$, and Neut phrases used in the scanning experiment. For the critical materials, 1 set of 45 phrases was sampled from each original set of $\mathrm{NC}+, \mathrm{NC}-, \mathrm{C}+$, and $\mathrm{C}$ - phrases (180 phrases total). For the fillers, 90 phrases were sampled from the original Neut phrases. Table 1 provides examples of these phrases.

As Supplementary Table S2 illustrates, the manipulations of valence and cancer relevance across the $\mathrm{NC}+, \mathrm{NC}-, \mathrm{C}+, \mathrm{C}-$, and Neut phrases were robust (overall means for valence: positive 6.23, neutral 4.18, negative 1.65) (overall means for cancer relevance: cancer 5.91, non-cancer 2.40, neutral 2.42). Additionally, the 5 sets of phrases were matched for phrase length and phrase final word. The only factor that couldn't be completely controlled was familiarity. Given that the positive phrases were rated as much more familiar than the negative phrases, matching was impossible (positive 6.23, neutral 4.82, negative 3.74 ). Increasingly positive phrases could actually be more frequent in the world, or perhaps reflect wishful thinking on the part of the raters that these events are frequent. Regardless, this difference does not bear on the later imaging results, given that it was held constant across groups and thus cannot be responsible for the group differences observed.

The phrases were also coded for whether they referred to bodily states, mental life, life activities, significant others, future events, disease, treatment, or medical events. As Supplemental Table S3 illustrates, all of the different types of phrase content occurred across the NC+, NC-, C+, C-, and Neut phrases.

For the 3 runs of the scanner experiment, 3 lists of 90 phrases were constructed, each containing $15 \mathrm{NC}+$ phrases, $15 \mathrm{NC}$ - phrases, $15 \mathrm{C}+$ phrases, $15 \mathrm{C}$ - phrases, and $30 \mathrm{Neut}$ phrases, randomly intermixed. An additional practice list was constructed from scaled phrases not sampled for the critical lists, containing $10 \mathrm{NC}+$ phrases, $10 \mathrm{NC}$ - phrases, $10 \mathrm{C}+$ phrases, $10 \mathrm{C}$ - phrases, and 20 Neut phrases, again randomly intermixed. A high-fidelity audio file of each phrase was recorded for auditory presentation in the experiment, using the same male voice with relatively neutral accent and affect.

\section{Procedure}

Within one week before the scan, each participant provided informed consent, underwent a thorough MRI screening procedure by phone, and received preliminary instructions about the 
scanning session (what to wear, what would happen, the importance of minimizing motion).

Meditators and cancer survivors knew that they had been sampled because they were meditators and cancer survivors. Nothing further was mentioned about the purpose of the experiment until the final debriefing.

After arriving in a lab on the day of the scan, participants underwent a second MRI screening and then received instructions on the task to be performed in the scanner (rating the familiarity of phrases heard over headphones). As an example, participants were given the phrase, "sunny day," and asked to judge whether it is something that they experience frequently, occasionally, or rarely. Participants were then shown how to indicate their familiarity judgments on a button box, as they would later do in the scanner. Once participants understood the task, they performed a practice run, making familiarity responses to each spoken phrase on the button box. A random inter-trial interval of 3 to 12 seconds followed each phrase, as would be the case later during scanning. Nothing was said explicitly to participants about the phrases varying in emotional valence and cancer relevance. Nevertheless, because the practice runs contained the same distribution of phrase types that occurred in the three critical scanning runs, participants most likely became aware that the phrases varied in valence and cancer/health relevance.

After travelling to the scanner in a nearby building, the scanning session began with a first anatomical (T1) scan and ended with a second one (each $\sim 5$ min). In between, participants performed 3 functional scans, 1 on each of the 3 critical lists (each $\sim 8.5 \mathrm{~min}$, separated by 5 min breaks). During each functional scan, participants listened to the 90 randomly intermixed phrases in a critical list over scanner-compatible headphones and made 1 of the 3 previously-practiced familiarity responses on a scanner-compatible button box. Random jitter between trials ranged from 3 to $12 \mathrm{sec}$ in an optimized sequence obtained from the optseq2 program (http://surfer.nmr.mgh.harvard.edu/optseq/). Half the participants received the 3 critical lists in one random order, and the other half received the lists in the reverse order. Total time in the scanner was $\sim 45 \mathrm{~min}$, followed by a subsequent debriefing session. Due to a programming error, behavioral data from the scanning session were not captured correctly, and so cannot be reported. 


\section{Image Acquisition and Analysis}

Anatomical and functional MRI scans were collected in a 3T Siemens Trio scanner at Emory University, using a 12-channel head coil and a scan sequence designed to minimize susceptibility artifacts while achieving a high signal-to-noise ratio (56 contiguous $2 \mathrm{~mm}$ slices in the axial plane, interleaved slice acquisition, $\mathrm{TR}=3000 \mathrm{~ms}, \mathrm{TE}=30 \mathrm{~ms}$, flip angle $=90^{\circ}$, bandwidth $=2442 \mathrm{~Hz} / \mathrm{Px}$, $\mathrm{FOV}=220 \mathrm{~mm}$, matrix $=64, \mathrm{iPAT}=2$, voxel size $=3.44 \times 3.44 \times 2 \mathrm{~mm})$.

Image processing using the AFNI platform included standard pre-processing steps, smoothing with a $6 \mathrm{~mm}$ kernel, and resampling to $2 \times 2 \times 2 \mathrm{~mm}$ voxels. Regression analysis was performed on individual participants using a Gamma function that modeled the $\mathrm{NC}+, \mathrm{NC}-, \mathrm{C}+, \mathrm{C}-$, and Neut phrases as events. The 11 regressors included 5 for the $\mathrm{NC}+, \mathrm{NC}-, \mathrm{C}+, \mathrm{C}-$, and Neut conditions, and 6 for motion parameters. One random-effects ANOVA was performed on each of the 3 participant groups to establish significant activations in each of the 5 conditions, relative to fixation baseline between trials. Significant clusters of neural activity were established using an individual voxel significance threshold of $p<.01$, and a cluster threshold that yielded a whole brain significance level of $p<.05$ corrected for multiple comparisons $(123,125$, and 120 resampled voxels for the meditators, cancer survivors, and controls, respectively; $984 \mathrm{~mm}^{3}, 1000 \mathrm{~mm}^{3}, 960 \mathrm{~mm}^{3}$ ). To provide further detail on brain activations, clusters down to 70 voxels are reported $\left(560 \mathrm{~mm}^{3}\right)$. The Supplementary Materials provide further details about the image acquisition and analysis procedures.

\section{Analysis Strategy}

As described earlier, our general hypothesis was that experienced meditators, cancer survivors, and matched controls would implicitly produce different emotional responses to the same affective stimuli, reflecting differences in their past emotional experience. Specifically, we expected different brain areas to become active in each group, as different sets of neural resources were assembled to produce implicit emotional responses.

To assess this hypothesis, we examined how each of the three groups responded to two basic contrasts in the critical stimulus set: (1) positive vs. negative phrases, (2) cancer vs. non-cancer phrases. If the three groups responded differently to positive vs. negative phrases, then the brain areas 
that became more active for positive phrases than for negative phrases should differ across groups, as should the brain areas that became more active for negative phrases. Analogously, if the three groups responded differently to cancer vs. non-cancer phrases, then the brain areas that became more active for cancer phrases than for non-cancer phrases should differ across groups, as should the brain areas that became more active for non-cancer phrases. As will become clear later, looking at particular patterns and brain areas within these differential patterns of responding allowed us to further assess our four specific hypotheses.

Linear contrasts. Within each of the three groups, two sets of linear contrasts were computed to implement our analysis strategy. In the first set, we contrasted positive vs. negative phrases, first, across cancer and non-cancer phrases together, and then for cancer and non-cancer phrases individually:

(C1) all positive phrases minus all negative phrases, $(\mathrm{C}+\& \mathrm{NC}+)$ minus $(\mathrm{C}-\& \mathrm{NC}-)$

(C2) positive cancer phrases minus negative cancer phrases, $\mathrm{C}+$ minus $\mathrm{C}$ -

(C3) positive non-cancer phrases minus negative non-cancer phrases, $\mathrm{NC}+$ minus NC-

In the second set of linear contrasts, we contrasted cancer vs. non-cancer phrases, first, across positive and negative phrases together, and then for positive and negative phrases individually:

(C4) all cancer phrases minus all non-cancer phrases, (C+\& C-) minus (NC+ \& NC-)

(C5) positive cancer phrases minus positive non-cancer phrases, $\mathrm{C}+$ minus $\mathrm{NC}+$

(C6) negative cancer phrases minus negative non-cancer phrases, C- minus NC-

To assess whether the neural activations established for each contrast differed across the three groups, we performed conjunction analyses, as described next.

Conjunction analyses. The control group was used as a baseline to establish population differences. On the one hand, did experienced meditators differ from controls in the brain areas active for a given contrast, demonstrating effects of meditation practice on emotional responses? On the other hand, did cancer survivors differ from controls, demonstrating effects of cancer experience? Thus, for each of the six contrasts above, one conjunction analysis compared the significant neural activations in experienced meditators with those for matched controls, whereas a second conjunction analysis compared the significant neural activations in cancer survivors with those for controls (a total 
of twelve analyses).

\section{Results}

Three sets of findings demonstrate that the experienced meditators, cancer survivors, and matched controls produced different emotional responses to the same critical phrases. First, the differential responses that each group made to positive vs. negative phrases had nothing in common; similarly, the differential responses that each group made to cancer vs. non-cancer phrases exhibited no overlap. Second, each group's responses to positive vs. negative phrases differed with respect to the overall patterns of activation and the specific brain areas active. Third, each group's responses to cancer vs. non-cancer phrases also differed with respect to activation patterns and active brain areas. We address each set of findings in turn.

\section{Absence of Overlapping Clusters Between Groups}

As described earlier, two conjunction analyses were computed for each of the six contrasts, with a first analysis assessing the overlapping activations between meditators and controls, and with a second assessing the overlap between cancer survivors and controls. To the extent that population differences exist in emotional responding, the overlap in these conjunction analyses should be low. Consider, for example, the overall contrast between positive vs. negative phrases (C1). If meditators and controls respond to positive and negative phrases differently, then the two groups should differ in the brain areas more active for positive than for negative phrases, and in the areas more active for negative than for positive phrases. Similarly, if cancer survivors and controls also respond to positive vs. negative phrases differently, then overlapping activations across the two groups in contrasts between positive and negative phrases should again be low.

The three groups responded so differently to the affective phrases that no significant shared clusters of activity emerged in any of the twelve conjunction analyses (at either the original cluster thresholds of 120-125 voxels, or at the lowered cluster threshold of 70 voxels). For the contrasts between positive and negative phrases in $\mathrm{C} 1, \mathrm{C} 2$, and $\mathrm{C} 3$, the clusters more active for positive phrases differed completely between meditators and controls, as did the clusters more active for negative phrases. In the analogous conjunction analyses between cancer survivors and controls, the clusters 
more active for positive phrases again differed completely, as did the clusters more active for negative phrases. The same absence of shared clusters occurred for the contrasts between cancer vs. noncancer phrases (C4, C5, and C6). No significant clusters of overlapping neural activity were more active for cancer phrases than for non-cancer phrases across meditators and controls, or across cancer survivors and controls. Similarly, no overlapping clusters were more active for the non-cancer phrases than for the cancer phrases across pairs of groups.

In three cases, small "splinters" of overlapping activations occurred on the fringes of slightly overlapping clusters across two groups, with each overlap being smaller than 70 voxels. For the overall contrast between positive and negative phrases $(\mathrm{C}+\& \mathrm{NC}+)$ minus $(\mathrm{C}-\& \mathrm{NC}-)$, an overlap of 12 voxels occurred in superior temporal cortex between two larger clusters separately active for cancer survivors and controls. For the contrast between positive cancer and positive non-cancer phrases $(\mathrm{C}+$ minus $\mathrm{NC}+$ ), an overlap of 39 voxels occurred in left postcentral (somatosensory) gyrus between two larger clusters separately active for meditators and controls, and an overlap of 19 voxels occurred in the left caudate between two larger clusters separately active for cancer survivors and controls. Not only were these shared activations small, they were few in number.

The absence of large overlapping activations between meditators, cancer survivors, and controls across the six contrasts supports our general hypothesis. The three groups did not show any substantial similarities in how they differentially responded to positive vs. negative phrases, nor in how they differentially responded to cancer vs. non-cancer phrases.

\section{Positive vs. Negative Emotion}

We next assess specific differences in how the three groups processed positive vs. negative emotion. For each group, what brain areas were more active for positive phrases than for negative phrases? What brain areas were more active for negative phrases than for positive phrases? As we will see, the three groups differed in their overall patterns of processing positive vs. negative emotion (as the lack of overlap between groups in the previous section implied).

For each group, Table 2 first presents brain areas more active for all positive phrases than for all negative phrases, followed by areas more active for all negative phrases (C1). Table 2 then breaks 
these results out separately for cancer phrases (C2) and for non-cancer phrases (C3). Figure 1 illustrates some of the activations in these contrasts.

Figure 2 presents the overall pattern for each group, summarizing how it differentially processed positive vs. negative emotion, once for each contrast. Values lying above the 0 point on the $\mathrm{Y}$ axis indicate the total number of clusters more active for positive phrases than for negative phrases; values lying below the 0 point on the $\mathrm{Y}$ axis indicate the number clusters more active for negative phrases than for positive phrases. Total clusters significant at the $p<.05$ cluster threshold are shown in the embedded bars. Many somewhat smaller activations $\geq 70$ voxels were observed in brain areas relevant to our hypotheses, and are, more generally, important for producing emotion (see recent meta-analyses by Kober et al., 2008; Lindquist Wager, Kober, Bliss-Moreau, \& Barrett, 2012). Because clusters at the 70-voxel threshold offer insight into population differences of interest, we focus on the results for this threshold, although clusters at both thresholds show the same general pattern, consistent with our hypotheses. The total number of voxels active across all relevant clusters at the 70-voxel threshold is also shown above each bar.

As all three panels of Figure 1 demonstrate, the overall patterns of neural activity for positive vs. negative phrases differed across the three populations, indicating that each population processed the positive and negative phrases differently. For cancer survivors, many brain areas were more active for positive phrases than for negative phrases across contrasts, but only one brain area was more active for negative phrases (in C3). Conversely, for matched controls, many brain areas were more active for negative phrases than for positive phrases across contrasts, but only two brain areas were more active for positive phrases (again in C3). Finally, experienced meditators differentiated much less between positive and negative phrases, given the relatively small numbers of brain areas more active for either positive or negative phrases.

For each of the three contrasts, the distribution of clusters for positive vs. negative phrases differed significantly across the three groups (for $\mathrm{C} 1, \chi^{2}(2)=12.62, p=.0018$; for $\mathrm{C} 2, \chi^{2}(2)=10.45, p$ $<.0054$; for $\mathrm{C} 3, \chi^{2}(2)=6.24, p<.0442$ ), as did the distribution of the total voxel counts summed across clusters (for $\mathrm{C} 1, \chi^{2}(2)=1763.94, p<.001$; for $\mathrm{C} 2, \chi^{2}(2)=1269.38, p<.001$; for $\mathrm{C} 3, \chi^{2}(2)=$ 
982.34, $p<.001)$. As these different patterns of neural activity indicate, the three groups processed positive and negative emotion differently.

As Table 2 further indicates, the specific brain areas producing the overall patterns of activity for positive and negative phrases differed considerably across groups as well. The same general brain area was almost never active across groups for positive phrases, nor for negative phrases (much less the same brain area, as we saw earlier for the absence of overlapping clusters). In the Discussion, we explore possible roles that activations in these brain areas may play in each population's experience of emotion.

\section{Cancer vs. Non-Cancer Phrases}

Finally, we assess differences in the neural responses to cancer vs. non-cancer phrases across the three groups. For each group, what brain areas were more active for cancer phrases than for noncancer phrases? What brain areas were more active for non-cancer phrases than for cancer phrases? As we will see, the three groups differed in their overall patterns of responding to each phrase type (as the lack of overlap between groups earlier implied).

For each group, Table 3 first presents brain areas more active for all cancer phrases than for all non-cancer phrases, followed by areas more active for all non-cancer phrases (C4). Table 3 then breaks these results out separately for positive phrases (C5) and for negative phrases (C6). Figure 3 illustrates some of the activations in these contrasts.

Figure 4 presents the overall pattern for each group, summarizing how it differentially processed cancer vs. non-cancer phrases, once for each contrast. Values lying above the 0 point on the $\mathrm{Y}$ axis indicate the total number of clusters more active for cancer phrases than for non-cancer phrases; values lying below the 0 point on the $\mathrm{Y}$ axis indicate the number of clusters more active for non-cancer phrases than for cancer phrases. Again, results are shown for two different cluster thresholds. Because clusters at the 70-voxel threshold offer insight into population differences of interest, we focus on them, although clusters at both thresholds show the same general pattern, consistent with our hypotheses.

As Figure 4 demonstrates, the strongest differences between groups emerged for positive 
phrases (C5). A weaker form of this pattern also occurred in the overall contrast across positive and negative phrases $(\mathrm{C} 4)$, reflecting the pattern for positive phrases. In contrast, differences between groups were largely absent for the negative phrases (C6), although control participants again exhibited more clusters and voxels trending in the negative direction (as also in C4 and C5).

For the positive phrases (C5), the overall patterns of neural activity for cancer vs. non-cancer phrases differed across the three populations, indicating that each population processed these cancer and non-cancer phrases differently. For meditators and cancer survivors, many brain areas were more active for cancer phrases than for non-cancer phrases. Conversely, for matched controls, many brain areas were more active for non-cancer phrases than for cancer phrases. Although meditators and cancer survivors exhibited roughly the same overall patterns, the specific brain areas producing these patterns differed almost completely, as Table 3 indicates (and as discussed later).

For contrasts $\mathrm{C} 5$ and $\mathrm{C} 4$, the distribution of clusters for cancer vs. non-cancer phrases differed significantly across the three groups (for C5, $\chi^{2}(2)=26.61, p<.001$; for $\mathrm{C} 4, \chi^{2}(2)=14.48, p=.0007$ ); for C6, the distribution of clusters for cancer vs. non-cancer phrases was independent of group $\left(\chi^{2}(2)\right.$ $=1.24, p=.5379)$. Again, the different distributions for the positive phrases (C5) appeared to be driving the overall differences for all phrases combined (C4). A similar pattern emerged for the distributions of total voxel counts summed across clusters, except that the distributions now also differed significantly for C6, roughly showing the same overall pattern as C5 and C4 (for C5, $\chi^{2}(2)=$ $3729.07, p<.001$; for $\mathrm{C} 4, \chi^{2}(2)=2260.51, p<.001$; for C6, $\left.\chi^{2}(2)=128.53, p<.001\right)$.

As Table 3 further indicates, the specific brain areas producing the overall patterns of activity for cancer and non-cancer phrases differed across groups for positive phrases, and also across positive and negative phrases together. In these two contrasts, the same general area was almost never active across all three groups for cancer phrases, nor for non-cancer phrases (much less the same area, as we saw earlier for the absence of overlapping clusters). In the Discussion, we explore possible roles that activations in these brain areas may play in each population's experience of emotion. 


\section{Discussion}

As constructivist theories of emotion predict, experienced meditators, cancer survivors, and matched controls differed in the neural resources that they recruited to process the same affective phrases. Three general results support this conclusion. First, the clusters of brain activity that distinguished positive vs. negative phrases did not overlap between populations, nor did the clusters that distinguished cancer vs. non-cancer phrases. Second, the overall patterns of brain activity associated with processing these phrases differed considerably across populations (Figures 2 and 4). Third, the specific brain areas underlying these patterns differed as well (Tables 2 and 3).

We next examine these results in greater detail. In particular, we speculate on the roles that the specific brain areas active for each group played in their differing emotional responses. Clearly, accepting these speculations with confidence requires further research. Nevertheless, we suggest these possibilities in the spirit of motivating future attempts to further understand the population differences presented here.

\section{Population Differences in Processing Positive vs. Negative Emotion}

We first examine the differing neural activations for positive vs. negative phrases across groups in Table 2, speculating on their implications for understanding how each population processed emotional valence.

Matched controls. For control participants, many more clusters (and total voxels) were active for negative phrases than for positive phrases, across all three contrasts (Figure 2). Controls distinguished negative phrases from positive phrases more than they distinguished positive phrases from negative phrases. One interpretation is that controls had more knowledge associated with negative phrases in memory than with positive phrases, such that more brain areas became active to process negative phrases. Another potentially compatible interpretation is that controls were more interested in the negative phrases than in the positive phrases, such that they engaged more with the negative phrases and processed them more deeply. Perhaps negative phrases were more self-relevant, such they received greater attention and elaboration. We will refer to these two possible interpretations as the knowledge hypothesis and the engagement hypothesis in later discussion. 
Neither hypothesis, one of them, or both could be correct. Establishing their validity requires further research aimed at examining them directly.

As described earlier, the three groups were matched for age (Table SM 1), with the average age of control participants being 37.2 years. Thus, control participants' strong orientation towards negative phrases is consistent with the general finding that younger- and middle-aged adults are more oriented towards negative information than towards positive information (e.g., Baumeister, Bratslavsky, Finkenauer, \& Vohs, 2001; Comblain, D’Argembeau, Van der Linden, \& Aldenhoff, 2004; Kensinger, O’Brien, Swanberg, Garoff-Eaton, \& Schacter, 2007; Rozin \& Royzman, 2001). One theory of this negative orientation is that it reflects the importance of handling negative situations effectively, thereby optimizing long-term goal achievement (Reed \& Carstensen, 2012). Regardless of how this negativity orientation originates, our middle-aged control participants demonstrated it.

Examining the specific brain areas in Table 2 active for control participants offers potential insight into how they processed the negative phrases. Across all negative phrases (both non-cancer and cancer), lateral orbitofrontal cortex (lOFC) was active bilaterally, suggesting that negative phrases may have produced stronger evaluative processing than did positive phrases (Rolls, 2004).

Activations in premotor and parahippocampal areas further suggest that negative phrases may have produced motor anticipation (Schubotz \& von Cramon, 2003) in environmental settings (Epstein, Graham, \& Downing, 2003), respectively.

Similar activations for the negative non-cancer phrases alone again suggest the importance of evaluation and situated action, as just described. Additional activation in the anterior cingulate activation suggests that the negative non-cancer phrases may have also elicited expectation violations and/or attempts at conflict resolution (Botvinick, Cohen, \& Carter, 2004). In contrast, the negative cancer phrases produced bilateral insula activation, suggesting that control participants found these events salient (Menon \& Uddin, 2010), experienced them interoceptively (Craig, 2009), and/or with disgust (Jabbi, Bastiaansen, \& Keysers, 2008). Notably, positive phrases generally produced none of these activations (except one small pre-motor cluster for the non-cancer phrases). Nor did any of these activations occur for the practiced mediators or cancer survivors, in response to exactly the same 
critical stimuli.

Cancer survivors. In contrast to how control participants appeared to adopt a negative orientation, cancer survivors appeared to adopt a positive orientation towards the same critical stimuli. Specifically, many more clusters (and total voxels) became active for positive phrases than for negative phrases in this group, across all three contrasts (Figure 2). Again, this positive orientation could reflect greater knowledge about positive phrases and/or greater engagement with them.

As described earlier, the literature on cancer recovery anticipates the positive orientation of our cancer survivors. Although some cancer survivors become depressed as a result of their illness, many become highly positive on recovering and receiving a second chance at life. Despite ongoing challenges (e.g., long-term side effects, uncertainty about the future), cancer survivors often develop a new positive outlook associated with greater meaning, purpose, and fulfillment, after facing their own mortality. As a result of this new outlook, cancer survivors may become increasingly engaged with positive events relative to negative ones, thereby establishing greater knowledge about positive events.

Examining the specific brain areas in Table 2 active for cancer survivors offers potential insight into how they processed the positive phrases. Across all three contrasts, primary and secondary auditory areas were active for positive phrases, suggesting that cancer survivors allocated greater auditory attention to the positive phrases than to negative ones (e.g., Jäncke, Buchanan, Lutz, $\&$ Shah, 2001). Notably, no such differences in auditory processing occurred for the matched controls or for the experienced meditators to the same critical stimuli, suggesting that only the cancer survivors were highly interested in the positive phrases per se, not just the events that these phrases described.

Positive phrases also activated the insula and $1 \mathrm{OFC}$ in cancer survivors, suggesting that their auditory orientation towards the positive phrases was accompanied by interoceptive processing (Bamiou, Musiek, \& Luxon, 2003) and evaluation (Kringelbach, 2005), respectively. Finally, positive phrases activated various motor, spatial, and visual areas (middle cingulate, inferior and superior parietal, cerebellum, precuneus), suggesting that cancer survivors prepared for situated action ((Barsalou, 2008, 2009). Cancer survivors may have been especially motivated to project themselves into situations associated with positive affect, consistent with the importance of maintaining hope 
following cancer (Felder, 2004).

Although the average age of our cancer participants was 44.1 years, their positive orientation could reflect changes in cognitive style similar to changes associated with aging in later years. As a large literature on cognitive aging documents, the increase in emotional positivity associated with aging late in life does not reflect a decline in brain function (Mather, 2012; Nashiro, Sakaki, \& Mather, 2012; Sakaki, Nga, \& Mather, 2013). Instead, increased positivity reflects changes in strategic processing associated with attention, memory, and choice (Isaacowitz, 2012; Reed \& Carstensen, 2012; Rovenpor, Skogsberg, \& Isaacowitz, 2013; Wadlinger \& Isaacowitz, 2011). As adults become older, they are more likely to self-select themselves into positive situations, to focus on positive events, and to establish positive memories. Older adults are also more likely to establish positive first impressions of others (Zebrowitz, Franklin Jr., Hillman, \& Boc, 2013).

As Reed and Carstensen (2012) propose, emotional positivity in aging may result from older adults focusing increasingly on the immediate future, instead of on longer-term life outcomes. Within this more limited time frame, it becomes important to minimize negative experiences so that positive and meaningful experiences can flourish, together with comfort and wellbeing. As noted earlier, a similar change in perspective can result from facing a life-threatening disease earlier in life. In our findings here, it is therefore not surprising perhaps that the cancer survivors exhibited a strong positivity bias. Not only did they attend more to positive auditory phrases than to negative ones, they also selected them for greater multimodal processing, suggesting a preference for projecting themselves into positive situations.

As described earlier, not all cancer survivors experience personal growth that results in a positive orientation. Instead, the experience of cancer can leave some individuals with lingering depression, PTSD, and distress, associated with experiencing life as lacking meaning and purpose (Bauer-Wu \& Farran, 2005; Jim \& Jacobsen, 2008). From the constructivist perspective, these individuals should exhibit a very different distribution of neural activations than the distribution observed for the cancer survivors here. Perhaps cancer survivors with a negative outlook would exhibit neural activity similar to the neural activity of our control participants. Quite possibly, 
however, they might instead exhibit a different profile, analogous to how experienced meditators and cancer survivors here both exhibited positive orientations towards cancer phrases that reflected different sets of neural resources (as described later).

Experienced meditators. Consistent with the hypothesis that meditation establishes equanimity, experienced meditators processed positive and negative phrases similarly. Although unique activations occurred for positive and negative phrases, they were small in number and size (Figure 2, Table 2). Unlike the strong negative and positive orientations that the controls and cancer survivors exhibited, respectively, meditators showed no strong bias towards one valence or the other. One possibility is that increasing meditation experience orients practitioners towards engaging with positive and negative events similarly. As a consequence, one kind of event does not initiate greater processing and elaboration than the other, such that greater knowledge is not established in memory.

Summary. Consistent with an orientation towards negative emotion in the non-elderly adult population, control participants were much more oriented toward negative emotion phrases than toward positive ones, focusing on evaluative, motor, and interoceptive aspects of the associated negative situations. In contrast, cancer survivors matched in age with the controls exhibited a strong orientation towards positive emotion, consistent with the prediction that surviving cancer can change one's perspective on life. Across multimodal processing areas associated with perception, action, and interoception, cancer survivors appeared more motivated to project themselves into positive situations than into negative ones. They also appeared to focus greater auditory attention on listening to positive emotional phrases. Finally, consistent with the prediction that equanimity results from regular meditation practice, experienced meditators did not show a stronger orientation towards positive or negative emotion, processing them similarly.

\section{Population Differences in Processing Cancer vs. Non-Cancer Phrases}

We next examine the differing neural activations for cancer vs. non-cancer phrases across groups in Table 3, speculating on their implications for understanding how each population processed events related to cancer. We begin with the group differences for positive phrases, and then turn to the relative lack of group differences for negative phrases. 
Positive phrases for control participants. As Figure 4 illustrates, control participants appeared much more oriented towards positive everyday events not associated with cancer than towards positive cancer events. Specifically, many more clusters (and total voxels) became active for the positive non-cancer phrases than for the positive cancer phrases. Consistent with the engagement hypothesis, this orientation could reflect control participants' greater willingness to engage with noncancer events and/or difficulty engaging with cancer events. Consistent with the knowledge hypothesis, this orientation could also reflect a relative lack of knowledge about events associated with cancer. Regardless of these possible interpretations, the pattern for control participants indicates that they distinguished positive non-cancer events from positive cancer events, but did not distinguish positive cancer events from positive non-cancer events.

Examining the specific brain areas in Table 3 active for control participants offers potential insight into how they processed the positive non-cancer phrases. Most notably, primary and secondary auditory areas became active, suggesting that controls allocated greater auditory attention to the positive non-cancer phrases than to the positive cancer phrases (e.g., Jäncke et al., 2001). Notably, no such differences in auditory processing occurred for the cancer survivors or experienced meditators to the same critical stimuli, indicating that only the controls exhibited greater relative interest in the positive non-cancer phrases.

A variety of other affective areas also became active for the positive non-cancer phrases in controls, including areas associated with evaluation (IOFC), interoception (insula), action (precentral cortex, caudate), somatosensory processing (postcentral), executive control (lateral prefrontal cortex), and basic bodily functions (brain stem). One interpretation of this pattern is that control participants projected themselves multimodally into positive non-cancer situations more than they projected themselves into positive cancer situations ((Barsalou, 2008, 2009). Again, this orientation could reflect greater interest in positive everyday situations and/or difficulty relating to positive cancer situations.

Positive phrases for experienced meditators. In contrast to control participants, experienced meditators showed the opposite overall pattern, exhibiting a stronger orientation toward cancer phrases 
than toward non-cancer phrases, activating more clusters and total voxels for cancer phrases. As predicted originally, this difference may reflect enhanced empathy and compassion skills established during meditation practice. As a result of acquiring these skills, experienced meditators may become increasingly willing to engage with challenging life events, such as cancer, thereby acquiring greater knowledge of them. Regardless of these possible interpretations, experienced meditators distinguished positive cancer events from positive non-cancer events, whereas matched controls did not.

The specific brain areas active when meditators processed positive cancer phrases suggest that they engaged with the respective events empathetically. As Table 3 illustrates, a large activation in medial prefrontal cortex suggests that meditators may have tried to adopt the mental states experienced in these events, or to mentalize about them in other ways (Frith \& Frith, 2006). Additional activations in visual areas (cuneus, precuneus), somatosensory areas (paracentral lobule, postcentral gyrus), and motor areas (middle cingulate) suggest that meditators may have tried to project themselves into positive cancer situations physically, as they mentalized about them (Uddin, Iacoboni, Lange, \& Keenan, 2007). Notably, meditators appeared to embody experience of these situations, given the activations in somatosensory and motor areas (de Vignemont, 2014; Jeannerod, 2001), perhaps reflecting a willingness to interact with cancer patients.

Positive phrases for cancer survivors. Similar to experienced meditators, cancer survivors were more oriented toward positive cancer phrases than toward positive non-cancer phrases. Importantly, however, the brain areas active for the cancer survivors while processing these phrases were very different from those active for the meditators (Table 3). Rather than activating multimodal brain areas associated with mentalizing, somatosensory experience, and action, cancer survivors only activated areas associated with visual processing. Perhaps most notably, they activated the extrastriate body area (EBA) bilaterally, a posterior region of occipital cortex that produces visual representations of the body (Downing, Jiang, Shuman, \& Kanwisher, 2001). Consistent with our prediction that bodily states would be central when cancer survivors processed affective phrases related to cancer, brain areas associated with bodily processing did indeed become active for cancer survivors.

Interestingly, however, brain areas associated with feeling and controlling the body did not 
become active, such as the insula, somatosensory cortex, and the motor system (some of which became active when meditators processed these same phrases). Instead, the other activations for cancer survivors all occurred in areas related to visual imagery (occipital cortex, precuneus, posterior cingulate cortex; Ganis, Thompson, \& Kosslyn, 2004). Rather than embodying experiences of how these phrases might feel "below the neck," cancer survivors may have represented the meanings of positive cancer phrases by visually simulating their body in surrounding contexts. Perhaps the cancer survivors were unwilling to embody these experiences for various reasons, or were attempting to visualize how they would appear in these events from a third-person perspective (Ruby \& Decety, 2001).

Summary for positive phrases. Consistent with our general hypothesis, controls, meditators, and cancer survivors varied considerably in their orientations towards cancer vs. non-cancer phrases associated with positive emotion. Whereas controls oriented more toward positive non-cancer phrases related to everyday situations, meditators and cancer survivors oriented more toward positive phrases related to cancer. Additionally, meditators and cancer survivors appeared to differ in how they processed positive cancer phrases. Whereas meditators processed these phrases in a multimodal manner, cancer survivors only processed them visually. Consistent with two of our specific predictions, cancer survivors appeared to process positive cancer phrases from a (visually) embodied perspective, whereas meditators appeared to exhibit empathy by orienting more toward the cancer phrases than did the controls. Again, these different orientations across groups could reflect differences in the willingness to engage with cancer and/or knowledge about it.

Negative phrases for all groups. As Table 3 illustrates for the final contrast (C6), all three groups distinguished negative cancer vs. non-cancer phrases minimally. Experienced meditators showed no differences between negative cancer and non-cancer phrases. Matched controls showed slightly more activation for non-cancer phrases in a motor area (superior frontal cortex, including the supplementary motor area, SMA) and in an evaluative area (IOFC). Cancer survivors showed slightly more activation for non-cancer phrases in the brain stem. Overall, all three groups produced relatively few activations for this contrast, indicating an absence of strong group differences in discriminating between cancer and non-cancer phrases associated with negative emotion. 
The relative absence of differences for the experienced meditators and cancer survivors conflicts with our original hypotheses. For cancer survivors, we predicted that their experience and interest in cancer would produce greater activation for cancer phrases (relative to non-cancer phrases) for both positive and negative emotion (not just for positive). For experienced meditators, we predicted that they would exhibit greater empathy and compassion than controls while processing cancer phrases, again regardless of whether the phrases were positive or negative.

One possibility that explains both departures from our predictions is that cancer survivors and meditators may have been reluctant to dwell on cancer phrases associated with negative emotion. Once cancer survivors and meditators realized that these phrases referred to negative situations, they may not have processed them further, perhaps as a regulatory strategy to minimize negative affect (Hayes, Wilson, Gifford, Follette, \& Strosahl, 1996; Silvers, Wager, Weber, \& Ochsner, 2014). As a result, cancer survivors didn't bring their expertise on cancer to bear, and meditators didn't apply their empathy and compassion skills. Because these population-specific resources weren't utilized to process emotion, the processing of negative cancer phrases resembled the processing of negative noncancer phrases.

Conversely, all groups may have processed the negative non-cancer phrases extensively, becoming highly engaged in them, similar to how they became highly engaged in the processing the negative cancer phrases. If so, then differences between the two types of phrases may not have emerged. Still another possibility is that, for cancer survivors, only positive cancer phrases may be related to personal growth, whereas negative cancer phrases may appear irrelevant or counterproductive. If so, then cancer survivors may have only focused additional neural resources related to self-growth on positive cancer phrases, not on negative ones. Better understanding the lack of differences for negative cancer and non-cancer phrases is another topic for future research.

\section{Exploring Population Differences Further}

The findings reported here demonstrate that individuals from three populations - experienced meditators, cancer survivors, and matched controls - processed the same set of affective stimuli differently. From the perspective of constructivist theories, each population's past emotional 
experience established different populations of situated conceptualizations in memory that contributed to its affective responses. Because experienced meditators established the mental qualities of equanimity, empathy, and compassion in previous emotional situations, they utilized neural resources associated with these qualities to process emotion. Because cancer survivors had embodied experiences with cancer, possibly experiencing significant personal growth as a result, the resultant mental qualities similarly contributed to their emotion processing.

These findings suggest that different populations process emotion in ways that are consistent with their previous experience. Future work could build upon our demonstration by examining and establishing the relationship between experience and emotion more precisely. For example, it would be productive to measure specific aspects of people's situated experience with emotion, and then use these measurements to predict specific behaviors and specific brain activity. Within cancer survivors, do emotional responses vary with the type of cancer and cancer treatment? Within meditators, do emotional responses vary as a function of the meditation tradition practiced? Rather than simply demonstrating differences between populations, it would be useful to establish specific relationships between aspects of experience and aspects of emotion. Understanding these relationships will increase our understanding of how neural resources related to emotion develop, and how these resources are assembled to produce emotional experience.

Another important direction for future work will be to establish relations between populationspecific emotion and related coping behaviors that follow from it. For example, once meditators establish the mental qualities of equanimity, empathy, and compassion, what specific effects do these qualities have on their actions in everyday situations? Similarly, when cancer survivors establish new ways of responding emotionally in everyday situations, how do the new emotions that they experience affect their behavior? Furthermore, in both examples, what effects do the outcomes of these actions have on other people in the respective situations?

Theoretically, much remains to be done in developing the constructivist account of emotion. What specific neural resources are recruited to produce emotion? What specific neural resources vary across populations for emotional states and why? Does different utilization of neural resources 
produce differences in emotion via knowledge and/or engagement? What kinds of experiences and interventions change these neural resources and the resultant emotions experienced (e.g., surviving cancer and meditation training)? How are situated conceptualizations of emotional experience established in affective situations, and how do they become stored in memory? When these emotional memories are retrieved on later occasions, how do they contribute to emotional experience, and how are they adapted to constraints of the current situation? How are the emotional styles associated with specific populations related to cultural differences in emotion? Addressing these issues effectively (and probably others) will be essential to an increased understanding of how emotion in different populations reflects past experience and serves future goals. 


\section{References}

Bamiou, D.-E., Musiek, F. E., \& Luxon, L. M. (2003). The insula (Island of Reil) and its role in auditory processing: Literature review. Brain Research Reviews, 42(2), 143-154.

Barrett, L. F. (2006a). Are emotions natural kinds? Perspectives on Psychological Science, 1(1), 2858.

Barrett, L. F. (2006b). Solving the emotion paradox: Categorization and the experience of emotion. Personality and Social Psychology Review, 10, 20-46.

Barsalou, L. W. (2003). Situated simulation in the human conceptual system. Language and Cognitive Processes, 18, 513-562.

Barsalou, L. W. (2008). Grounded Cognition. Annual Review of Psychology, 59, 617-645.

Barsalou, L. W. (2009). Simulation, situated conceptualization, and prediction. Philosophical Transactions of the Royal Society B: Biological Sciences, 364(1521), 1281-1289.

Barsalou, L. W. (2013). Mirroring as pattern completion inferences within situated conceptualizations. Cortex, 49, 2951-2953.

Barsalou, L. W., Niedenthal, P. M., Barbey, A. K., \& Ruppert, J. A. (2003). Social embodiment. In Psychology of Learning and Motivation (Vol. Volume 43, pp. 43-92). Academic Press.

Bauer-Wu, S., \& Farran, C. J. (2005). Meaning in Life and Psycho-Spiritual Functioning A Comparison of Breast Cancer Survivors and Healthy Women. Journal of Holistic Nursing, 23(2), 172-190.

Baumeister, R. F., Bratslavsky, E., Finkenauer, C., \& Vohs, K. D. (2001). Bad is stronger than good. Review of General Psychology, 5(4), 323-370.

Bell, K. (2012). Remaking the Self: Trauma, Teachable Moments, and the Biopolitics of Cancer Survivorship. Culture, Medicine, and Psychiatry, 36(4), 584-600.

Botvinick, M. M., Cohen, J. D., \& Carter, C. S. (2004). Conflict monitoring and anterior cingulate cortex: an update. Trends in Cognitive Sciences, 8(12), 539-546.

Bower, J. E., Meyerowitz, B. E., Bernaards, C. A., Rowland, J. H., Ganz, P. A., \& Desmond, K. A. (2005). Perceptions of positive meaning and vulnerability following breast cancer: Predictors 
and outcomes among long-term breast cancer survivors. Annals of Behavioral Medicine, 29(3), $236-245$.

Brefczynski-Lewis, J. A., Lutz, A., Schaefer, H. S., Levinson, D. B., \& Davidson, R. J. (2007). Neural correlates of attentional expertise in long-term meditation practitioners. Proceedings of the National Academy of Sciences, 104(27), 11483-11488.

Bullen, T. L., Sharpe, L., Lawsin, C., Patel, D. C., Clarke, S., \& Bokey, L. (2012). Body image as a predictor of psychopathology in surgical patients with colorectal disease. Journal of Psychosomatic Research, 73(6), 459-463.

Carlson, L. E., \& Thomas, B. C. (2007). Development of the calgary symptoms of stress inventory (csosi). International Journal of Behavioral Medicine, 14(4), 249-256.

Chambers, R., Gullone, E., \& Allen, N. B. (2009). Mindful emotion regulation: An integrative review. Clinical Psychology Review, 29(6), 560-572.

Comblain, C., D’Argembeau, A., Van der Linden, M., \& Aldenhoff, L. (2004). The effect of ageing on the recollection of emotional and neutral pictures. Memory, 12(6), 673-684.

Condon, P., Desbordes, G., Miller, W., \& DeSteno, D. (2013). Meditation increases compassionate responses to suffering. Psychological Science, 24(10), 2125-2127.

Connerty, T. J., \& Knott, V. (2013). Promoting positive change in the face of adversity: experiences of cancer and post-traumatic growth. European Journal of Cancer Care, 22(3), 334-344.

Cordova, M. J., Giese-Davis, J., Golant, M., Kronenwetter, C., Chang, V., \& Spiegel, D. (2007). Breast Cancer as Trauma: Posttraumatic Stress and Posttraumatic Growth. Journal of Clinical Psychology in Medical Settings, 14(4), 308-319.

Craig, A. D. (2009). How do you feel - now? The anterior insula and human awareness. Nature Reviews Neuroscience, 10(1), 59-70.

De Vignemont, F. (2014). Shared body representations and the "Whose" system. Neuropsychologia, $55,128-136$.

Desbordes, G., Negi, L. T., Pace, T. W. W., Wallace, B. A., Raison, C. L., \& Schwartz, E. L. (2012). Effects of mindful-attention and compassion meditation training on amygdala response to 
emotional stimuli in an ordinary, non-meditative state. Frontiers in Human Neuroscience, 6.

Dirksen, S. R. (1995). Search for meaning in long-term cancer survivors. Journal of Advanced Nursing, 21(4), 628-633.

Downing, P. E., Jiang, Y., Shuman, M., \& Kanwisher, N. (2001). A cortical area selective for visual processing of the human body. Science, 293(5539), 2470-2473.

Dunn, J., Campbell, M., Penn, D., Dwyer, M., \& Chambers, S. K. (2009). Amazon Heart: an exploration of the role of challenge events in personal growth after breast cancer. Journal of Psychosocial Oncology, 27(1), 119-135.

Epstein, R., Graham, K. S., \& Downing, P. E. (2003). Viewpoint-Specific Scene Representations in Human Parahippocampal Cortex. Neuron, 37(5), 865-876.

Falk Dahl, C. A., Reinertsen, K. V., Nesvold, I.-L., Fossa, S. D., \& Dahl, A. A. (2010). A study of body image in long-term breast cancer survivors. Cancer, 116(15), 3549-3557.

Felder, B. E. (2004). Hope and coping in patients with cancer diagnoses. Cancer Nursing, 27(4), 320324.

Fobair, P., Stewart, S. L., Chang, S., D’Onofrio, C., Banks, P. J., \& Bloom, J. R. (2006). Body image and sexual problems in young women with breast cancer. Psycho-Oncology, 15(7), 579-594.

Fredrickson, B. L. (2001). The role of positive emotions in positive psychology: The broaden-andbuild theory of positive emotions. American Psychologist, 56(3), 218.

Fredrickson, B. L., Cohn, M. A., Coffey, K. A., Pek, J., \& Finkel, S. M. (2008). Open hearts build lives: Positive emotions, induced through loving-kindness meditation, build consequential personal resources. Journal of Personality and Social Psychology, 95(5), 1045-1062.

Frith, C. D., \& Frith, U. (2006). The neural basis of mentalizing. Neuron, 50(4), 531-534.

Ganis, G., Thompson, W. L., \& Kosslyn, S. M. (2004). Brain areas underlying visual mental imagery and visual perception: an fMRI study. Cognitive Brain Research, 20(2), 226-241.

Gendron, M., \& Feldman Barrett, L. (2009). Reconstructing the Past: A Century of Ideas About Emotion in Psychology. Emotion Review, 1(4), 316-339.

Given, C. W., \& Given, B. A. (2013). Symptom Management and Psychosocial Outcomes Following 
Cancer. In Seminars in Oncology (Vol. 40, pp. 774-783). Elsevier.

Gotay, C. C., \& Muraoka, M. Y. (1998). Quality of Life in Long-Term Survivors of Adult-Onset Cancers. Journal of the National Cancer Institute, 90(9), 656-667.

Hayes, S. C., Wilson, K. G., Gifford, E. V., Follette, V. M., \& Strosahl, K. (1996). Experiential avoidance and behavioral disorders: A functional dimensional approach to diagnosis and treatment. Journal of Consulting and Clinical Psychology, 64(6), 1152.

Hofmann, S. G., Grossman, P., \& Hinton, D. E. (2011). Loving-kindness and compassion meditation: Potential for psychological interventions. Clinical Psychology Review, 31(7), 1126-1132.

Huffziger, S., Ebner-Priemer, U., Eisenbach, C., Koudela, S., Reinhard, I., Zamoscik, V., ... Kuehner, C. (2013). Induced ruminative and mindful attention in everyday life: An experimental ambulatory assessment study. Journal of Behavior Therapy and Experimental Psychiatry, $44(3), 322-328$.

Isaacowitz, D. M. (2012). Mood Regulation in Real Time Age Differences in the Role of Looking. Current Directions in Psychological Science, 21(4), 237-242.

Jabbi, M., Bastiaansen, J., \& Keysers, C. (2008). A Common Anterior Insula Representation of Disgust Observation, Experience and Imagination Shows Divergent Functional Connectivity Pathways. PLoS ONE, 3(8), e2939.

Jäncke, L., Buchanan, T. W., Lutz, K., \& Shah, N. J. (2001). Focused and Nonfocused Attention in Verbal and Emotional Dichotic Listening: An FMRI Study. Brain and Language, 78(3), 349363.

Jazaieri, H., Jinpa, G. T., McGonigal, K., Rosenberg, E. L., Finkelstein, J., Simon-Thomas, E., ... Goldin, P. R. (2013). Enhancing Compassion: A Randomized Controlled Trial of a Compassion Cultivation Training Program. Journal of Happiness Studies, 14(4), 1113-1126.

Jeannerod, M. (2001). Neural Simulation of Action: A Unifying Mechanism for Motor Cognition. NeuroImage, 14(1), S103-S109. doi:10.1006/nimg.2001.0832

Jim, H. S., \& Jacobsen, P. B. (2008). Posttraumatic stress and posttraumatic growth in cancer survivorship: a review. The Cancer Journal, 14(6), 414-419. 
Jim, H. S., Purnell, J. Q., Richardson, S. A., Golden-Kreutz, D., \& Andersen, B. L. (2006). Measuring meaning in life following cancer. Quality of Life Research : An International Journal of Quality of Life Aspects of Treatment, Care and Rehabilitation, 15(8), 1355-1371.

Kashdan, T. B., \& Kane, J. Q. (2011). Post-traumatic distress and the presence of post-traumatic growth and meaning in life: Experiential avoidance as a moderator. Personality and Individual Differences, 50(1), 84-89.

Kensinger, E. A., O’Brien, J. L., Swanberg, K., Garoff-Eaton, R. J., \& Schacter, D. L. (2007). The effects of emotional content on reality-monitoring performance in young and older adults. Psychology and Aging, 22(4), 752-764.

Kernan, W. D., \& Lepore, S. J. (2009). Searching for and making meaning after breast cancer: Prevalence, patterns, and negative affect. Social Science \& Medicine, 68(6), 1176-1182.

Klimecki, O. M., Leiberg, S., Lamm, C., \& Singer, T. (2012). Functional Neural Plasticity and Associated Changes in Positive Affect After Compassion Training. Cerebral Cortex, 23(7), $1552-1561$.

Kober, H., Barrett, L. F., Joseph, J., Bliss-Moreau, E., Lindquist, K., \& Wager, T. D. (2008). Functional grouping and cortical-subcortical interactions in emotion: A meta-analysis of neuroimaging studies. NeuroImage, 42(2), 998-1031.

Komura, K., \& Hegarty, J. R. (2006). The appraisal of positive life changes following cancer diagnosis: An interview study. Palliative \& Supportive Care, 4(01), 3-12.

Kringelbach, M. L. (2005). The human orbitofrontal cortex: linking reward to hedonic experience. Nature Reviews Neuroscience, 6(9), 691-702.

Krumwiede, K. A., \& Krumwiede, N. (2012). The lived experience of men diagnosed with prostate cancer. In Oncology Nursing Forum (Vol. 39, pp. E443-E450). Oncology Nursing Society.

Lazarus, R. S. (2001). Relational meaning and discrete emotions. In K. R. Scherer, A. Schorr, \& T. Johnstone (Eds.), Appraisal processes in emotion: Theory, methods, research (pp. 37-67). New York, NY, US: Oxford University Press.

Lench, H. C., Flores, S. A., \& Bench, S. W. (2011). Discrete emotions predict changes in cognition, 
judgment, experience, behavior, and physiology: A meta-analysis of experimental emotion elicitations. Psychological Bulletin, 137(5), 834-855.

Lindquist, K. A., Wager, T. D., Kober, H., Bliss-Moreau, E., \& Barrett, L. F. (2012). The brain basis of emotion: A meta-analytic review. Behavioral and Brain Sciences, 35(03), 121-143.

Linley, P. A., \& Joseph, S. (2004). Positive Change Following Trauma and Adversity: A Review. Journal of Traumatic Stress, 17(1), 11-21.

Lo, C., Zimmermann, C., Rydall, A., Walsh, A., Jones, J. M., Moore, M. J., ... Rodin, G. (2010). Longitudinal study of depressive symptoms in patients with metastatic gastrointestinal and lung cancer. Journal of Clinical Oncology, 28(18), 3084-3089.

Lutz, A., Brefczynski-Lewis, J., Johnstone, T., \& Davidson, R. J. (2008). Regulation of the Neural Circuitry of Emotion by Compassion Meditation: Effects of Meditative Expertise. PLoS ONE, 3(3), e1897.

Lutz, A., Greischar, L. L., Perlman, D. M., \& Davidson, R. J. (2009). BOLD signal in insula is differentially related to cardiac function during compassion meditation in experts vs. novices. NeuroImage, 47(3), 1038-1046.

Margolin, E. (n.d.). How Antoinette Tuff was trained to be a hero. MSNBC. Retrieved October 6, 2013, from http://tv.msnbc.com/2013/08/22/how-to-train-a-hero-what-schools-can-learn-fromantoinette-tuff/

Mascaro, J. S., Rilling, J. K., Negi, L. T., \& Raison, C. L. (2013). Pre-existing brain function predicts subsequent practice of mindfulness and compassion meditation. NeuroImage, 69, 35-42.

Mather, M. (2012). The emotion paradox in the aging brain. Annals of the New York Academy of Sciences, 1251, 33-49.

Menon, V., \& Uddin, L. Q. (2010). Saliency, switching, attention and control: a network model of insula function. Brain Structure and Function, 214(5-6), 655-667.

Moyer, C. A., Donnelly, M. P. W., Anderson, J. C., Valek, K. C., Huckaby, S. J., Wiederholt, D. A., ... Rice, B. L. (2011). Frontal Electroencephalographic Asymmetry Associated With Positive Emotion Is Produced by Very Brief Meditation Training. Psychological Science, 22(10), 
$1277-1279$.

Mystakidou, K., Parpa, E., Tsilika, E., Pathiaki, M., Galanos, A., \& Vlahos, L. (2007). Traumatic Distress and Positive Changes in Advanced Cancer Patients. American Journal of Hospice and Palliative Medicine, 24(4), 270-276.

Nashiro, K., Sakaki, M., \& Mather, M. (2012). Age differences in brain activity during emotion processing: reflections of age-related decline or increased emotion regulation? Gerontology, $58(2), 156-163$.

Pace, T. W. W., Negi, L. T., Adame, D. D., Cole, S. P., Sivilli, T. I., Brown, T. D., ... Raison, C. L. (2009). Effect of compassion meditation on neuroendocrine, innate immune and behavioral responses to psychosocial stress. Psychoneuroendocrinology, 34(1), 87-98.

Park, C. L., Chmielewski, J., \& Blank, T. O. (2010). Post-traumatic growth: finding positive meaning in cancer survivorship moderates the impact of intrusive thoughts on adjustment in younger adults. Psycho-Oncology, 19(11), 1139-1147.

Park, C. L., Lechner, S. C., Antoni, M. H., \& Stanton, A. L. (2009). Medical illness and positive life change: Can crisis lead to personal transformation? (Vol. xv). Washington, DC, US: American Psychological Association.

Park, C. L., Zlateva, I., \& Blank, T. O. (2009). Self-identity After Cancer: "Survivor”, "Victim”, “Patient”, and "Person with Cancer." Journal of General Internal Medicine, 24(Suppl 2), 430435.

Parry, D. C. (2008). The Contribution of Dragon Boat Racing to Women's Health and Breast Cancer Survivorship. Qualitative Health Research, 18(2), 222-233.

Reed, A. E., \& Carstensen, L. L. (2012). The Theory Behind the Age-Related Positivity Effect. Frontiers in Psychology, 3.

Ricard, M. (2007). Happiness: a guide to developing life's most important skill. London: Atlantic.

Rolls, E. T. (2004). The functions of the orbitofrontal cortex. Brain and Cognition, 55(1), 11-29.

Rovenpor, D. R., Skogsberg, N. J., \& Isaacowitz, D. M. (2013). The choices we make: An examination of situation selection in younger and older adults. Psychology and Aging, 28(2), 
$365-376$.

Rozin, P., \& Royzman, E. B. (2001). Negativity Bias, Negativity Dominance, and Contagion. Personality and Social Psychology Review, 5(4), 296-320.

Ruby, P., \& Decety, J. (2001). Effect of subjective perspective taking during simulation of action: a PET investigation of agency. Nature Neuroscience, 4(5), 546-550.

Sabiston, C. M., McDonough, M. H., \& Crocker, P. R. (2007). Psychosocial experiences of breast cancer survivors involved in a dragon boat program: exploring links to positive psychological growth. Journal of Sport and Exercise Psychology, 29(4), 419-438.

Sakaki, M., Nga, L., \& Mather, M. (2013). Amygdala functional connectivity with medial prefrontal cortex at rest predicts the positivity effect in older adults' memory. Journal of Cognitive Neuroscience, 25(8), 1206-1224.

Salzberg, S. (2002). Loving kindness: The revolutionary art of happiness. Boston: Shambala.

Schubotz, R. I., \& von Cramon, D. Y. (2003). Functional-anatomical concepts of human premotor cortex: evidence from fMRI and PET studies. NeuroImage, 20, S120-S131.

Sharpe, L., Patel, D., \& Clarke, S. (2011). The relationship between body image disturbance and distress in colorectal cancer patients with and without stomas. Journal of Psychosomatic Research, 70(5), 395-402.

Silvers, J. A., Wager, T. D., Weber, J., \& Ochsner, K. N. (2014). The neural bases of uninstructed negative emotion modulation. Social Cognitive and Affective Neuroscience, nsu016.

Taylor, V. A., Grant, J., Daneault, V., Scavone, G., Breton, E., Roffe-Vidal, S., .. Beauregard, M. (2011). Impact of mindfulness on the neural responses to emotional pictures in experienced and beginner meditators. NeuroImage, 57(4), 1524-1533.

Tedeschi, R. G., Tedeschi, R. G., Park, C. L., \& Calhoun, L. G. (1998). Posttraumatic growth: Positive changes in the aftermath of crisis. Routledge.

Uddin, L. Q., Iacoboni, M., Lange, C., \& Keenan, J. P. (2007). The self and social cognition: the role of cortical midline structures and mirror neurons. Trends in Cognitive Sciences, 11(4), 153157. 
Wadlinger, H. A., \& Isaacowitz, D. M. (2011). Fixing our focus: Training attention to regulate emotion. Personality and Social Psychology Review, 15(1), 75-102.

Watson, D., \& Clark, L. A. (1999). The PANAS-X: Manual for the positive and negative affect schedule-expanded form. Retrieved from http://ir.uiowa.edu/cgi/viewcontent.cgi?article=1011\&context=psychology_pubs

Weng, H. Y., Fox, A. S., Shackman, A. J., Stodola, D. E., Caldwell, J. Z. K., Olson, M. C., ... Davidson, R. J. (2013). Compassion Training Alters Altruism and Neural Responses to Suffering. Psychological Science, 24(7), 1171-1180.

Wilson-Mendenhall, C. D., Barrett, L. F., Simmons, W. K., \& Barsalou, L. W. (2011). Grounding emotion in situated conceptualization. Neuropsychologia, 49(5), 1105-1127.

Yeh, W., \& Barsalou, L. W. (2006). The situated nature of concepts. The American Journal of Psychology, 119, 349.

Zebrowitz, L. A., Franklin Jr., R. G., Hillman, S., \& Boc, H. (2013). Older and younger adults' first impressions from faces: Similar in agreement but different in positivity. Psychology and Aging, 28(1), 202-212. 


\section{Author Notes}

Work on this project was supported by a grant from the Robert W. Woodruff Health Sciences Center Fund to Susan Bauer-Wu (with co-investigators Lawrence W. Barsalou, Andrew J. Butler, Giuseppe Pagnoni, and John D. Dunne). We are grateful to Taryn Colton for assistance with reviewing relevant literature and to Esther Papies for helpful discussion. SBW obtained funding for the project. LWB, SBW, and AJB coordinated it. SBW, LWB, AJB, JKR, RW, GP, WH, WKS, JDD, and BOdS contributed to conceptualizing the design and hypotheses, and to developing the scaled set of phrases presented to participants. AJB, JKR, LWB, and SBW played central roles in implementing the experiment. JKR and AJB wrote the eprime code for the experiment and ran participants. LWB performed the primary analyses, with GP, WKS, WH, CDWM, LAML, and JHD contributing expertise and secondary analyses. LWB prepared the figures and tables, and wrote the initial draft of the manuscript. All authors contributed to the interpretation of the data, and to manuscript revision. All authors approved the final version for submission. 


\section{Figure Captions}

Figure 1. Examples of brain areas more active for negative phrases than for positive phrases in control participants, and of brain areas more active for positive phrases than for all negative phrases in cancer survivors.

Figure 2. Total number of clusters ( $\mathrm{Y}$ axis) and total number of voxels across clusters (tops of bars) that were more active for positive vs. negative phrases at an independent voxel threshold of $p<.01$ and a cluster threshold of 70 contiguous voxels, shown once for all phrases (C1), cancer phrases (C2), and non-cancer phrases (C3). Total clusters significant at the $p<.05$ cluster threshold are shown in the embedded bars. Values lying above the 0 point on the $\mathrm{Y}$ axis represent total clusters more active for positive phrases than for negative phrase; values lying below the 0 point represent total clusters more active for negative phrases than for positive phrases. Clusters for meditators were obtained from a conjunction analysis between meditators and controls; clusters for cancer survivors were obtained from a conjunction analysis between cancer survivors and controls. Clusters for controls were the same in both analyses, given that no significant overlaps between participant groups occurred in either analysis. See Table 2 for detailed presentation of the clusters.

Figure 3. Examples of brain areas more active for positive non-cancer phrases than for positive cancer phrases in control participants, and of brain areas more active for positive cancer phrases than for positive non-cancer phrases in experienced meditators and in cancer survivors.

Figure 4. Total number of clusters ( $\mathrm{Y}$ axis) and total number of voxels across clusters (tops of bars) that were more active for cancer vs. non-cancer phrases at an independent voxel threshold of $p<.01$ and a cluster threshold of 70 contiguous voxels, shown once for all phrases (C4), positive phrases (C5), and negative phrases (C6). Total clusters significant at the $p<.05$ cluster threshold are shown in the embedded bars. Values lying above the 0 point on the $\mathrm{Y}$ axis represent total clusters more active for cancer phrases than for non-cancer phrase; values lying below the 0 point represent total clusters 
more active for non-cancer phrases than for cancer phrases. Clusters for meditators were obtained from a conjunction analysis between meditators and controls; clusters for cancer survivors were obtained from a conjunction analysis between cancer survivors and controls. Clusters for controls were the same in both analyses, given that no significant overlaps between participant groups occurred in either analysis. See Table 3 for detailed presentation of the clusters. 
Table 1. Examples of the critical phrases used in the scanning session.

\section{Positive Non-Cancer (NC+)}

kind heart

warm hug

relaxing bath

fulfilled goals

healthy relationships

watching the sunset

all working together

\section{Positive Cancer $(\mathbf{C}+)$}

in remission

normal blood counts

treatment tolerated well

beat the disease

full-bodied hair

tasting food again

strong immune system
Negative Non-Cancer (NC-)

job loss

mean co-workers

tooth loss

bad breath

overdrawn account

not measuring up

dishonest spouse

\section{Negative Cancer (C-)}

metastatic cancer

full of toxins

scary procedure

leaving others behind

bald head

bone aches

cancer recurrence

\section{Neutral (Neut)}

brushing teeth

meeting co-workers

thinking so what

watching television

ring finger

stretching routine

front desk receptionist

Note. All critical and practice phrases used in the experiment can be found in Supplemental Table S4. 
Table 2. Significant activations in contrasts between positive and negative phrases from two conjunction analyses (meditators vs. controls; cancer survivors vs. controls).

\begin{tabular}{|c|c|c|c|c|c|c|c|c|c|c|}
\hline \multicolumn{4}{|c|}{ Meditators } & \multicolumn{3}{|c|}{ Controls } & \multicolumn{4}{|c|}{ Cancer Survivors } \\
\hline \multicolumn{2}{|r|}{$\begin{array}{l}\text { cluster } \\
\text { volume }\end{array}$} & \multicolumn{2}{|c|}{$\frac{\text { max intensity voxel }}{\mathrm{X} \mathrm{Y} \mathrm{Z} \mathrm{Peak} t}$} & brain region & \multicolumn{2}{|c|}{$\frac{\text { max intensity voxel }}{\mathrm{X} Y \mathrm{Z} \text { Peak } t}$} & brain region & $\begin{array}{l}\text { cluster } \\
\text { volume }\end{array}$ & \multicolumn{2}{|c|}{ max intensity voxel } \\
\hline \multicolumn{11}{|c|}{$\begin{array}{c}\text { Positive All > Negative All } \\
(\mathrm{NC}+\& \mathrm{C}+) \text { minus (NC- \& C-) }\end{array}$} \\
\hline & & & & & & & $\begin{array}{l}\text { R auditory / } \\
\text { inferior parietal, } \\
\text { BA } 41 / 42 / 22 / 40\end{array}$ & 240 & $55-4322$ & 6.550 \\
\hline & & & & & & & $\begin{array}{l}\text { middle cingulate, } \\
\text { BA } 24 / 31\end{array}$ & 234 & $3-156$ & 8.956 \\
\hline & & & & & & & $\mathrm{L}$ insula & 149 & -57132 & 6.423 \\
\hline & & & & & & & $\begin{array}{l}\text { L middle/superior, } \\
\text { temporal, BA } 21 / 22\end{array}$ & 136 & $-45-356$ & 6.790 \\
\hline & & & & & & & $\begin{array}{l}\text { L inferior parietal, } \\
\text { BA } 40\end{array}$ & 89 & $-53-3132$ & 7.151 \\
\hline & & & & & & & $\begin{array}{l}\text { R middle temporal } \\
\text { BA } 20 / 37\end{array}$ & 77 & $55-45-10$ & 6.008 \\
\hline \multicolumn{11}{|c|}{$\begin{array}{c}\text { Negative All }>\text { Positive All } \\
(\mathrm{NC}-\& \mathrm{C}-) \text { minus }(\mathrm{NC}+\& \mathrm{C}+)\end{array}$} \\
\hline \multirow[t]{5}{*}{$\begin{array}{l}\text { R superior temporal / } \\
\text { TPJ, BA } 39\end{array}$} & 73 & $51-5122$ & -6.306 & $\begin{array}{l}\text { L OFC, temporal pole, } 285 \\
\text { superior/middle temporal, } \\
\text { BA } 47 / 38 / 22 / 21\end{array}$ & $-45 \quad 1-16$ & -5.292 & & & & \\
\hline & & & & R OFC, BA 47 & $3941-8$ & -4.941 & & & & \\
\hline & & & & L middle frontal, BA 692 & -15748 & -6.977 & & & & \\
\hline & & & & L parahippocampal 89 & $-29-35-12$ & -6.892 & & & & \\
\hline & & & & R OFC, BA 47 & $3919-12$ & -7.578 & & & & \\
\hline
\end{tabular}




\begin{tabular}{|c|c|c|c|c|c|c|c|c|c|c|c|}
\hline \multicolumn{4}{|c|}{ Meditators } & \multicolumn{4}{|c|}{ Controls } & \multicolumn{4}{|c|}{ Cancer Survivors } \\
\hline brain region & $\begin{array}{l}\text { cluster } \\
\text { volume }\end{array}$ & \multicolumn{2}{|c|}{ max intensity voxel } & brain region & $\begin{array}{l}\text { cluster } \\
\text { volume }\end{array}$ & \multicolumn{2}{|c|}{ max intensity voxel } & \multirow{2}{*}{ brain region } & $\begin{array}{l}\text { cluster } \\
\text { volume }\end{array}$ & \multicolumn{2}{|c|}{ max intensity voxe } \\
\hline & & & & Cancer Positi & $\begin{array}{l}\text { ve }>\mathbf{C} \\
+ \text { minus }\end{array}$ & $\begin{array}{l}\text { ancer Neg } \\
\text { C- }\end{array}$ & ative & & & & \\
\hline \multirow[t]{9}{*}{ L postcentral, BA 3} & 83 & $-45-2154$ & 5.964 & & & & & $\begin{array}{l}\text { R auditory, } \\
\text { BA 41/42/21/22 }\end{array}$ & 184 & & 7.914 \\
\hline & & & & & & & & $\begin{array}{l}\text { middle cingulate, } \\
\text { BA } 32\end{array}$ & 94 & $\begin{array}{lll}-3 & -9 & 48\end{array}$ & 6.583 \\
\hline & & & & & & & & $\begin{array}{l}\text { R TPJ / } \\
\text { precuneus, BA 39/19 }\end{array}$ & 89 & $37-6134$ & 12.057 \\
\hline & & & & & & & & $\mathrm{R}$ sup temporal, BA 22 & 2287 & $55-4322$ & 6.553 \\
\hline & & & & \multicolumn{4}{|c|}{$\begin{array}{c}\text { Cancer Negative }>\text { Cancer Positive } \\
\text { C- minus C+ }\end{array}$} & & & & \\
\hline & & & & $\begin{array}{l}\text { L insula (middle), } \\
\text { claustrum }\end{array}$ & 184 & $\begin{array}{lll}-33 & 1 & -6\end{array}$ & -5.769 & & & & \\
\hline & & & & $\begin{array}{l}\text { R middle temporal, } \\
\text { BA } 21\end{array}$ & 128 & $61-41-4$ & -5.405 & & & & \\
\hline & & & & $\mathrm{R}$ insula (middle) & 118 & $\begin{array}{lll}39 & 7 & 0\end{array}$ & -5.208 & & & & \\
\hline & & & & $\begin{array}{l}\text { L anterior/superior } \\
\text { temporal, } \sim \text { BA } 38\end{array}$ & 83 & $-39 \quad 3-16$ & -6.689 & & & & \\
\hline
\end{tabular}




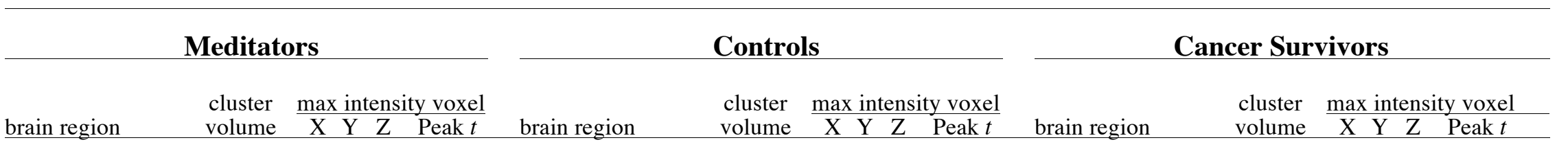

Non-Cancer Positive $>$ Non-Cancer Negative

$\mathrm{NC}+$ minus NC-

\begin{tabular}{|c|c|c|c|c|c|c|c|c|c|c|c|}
\hline \multirow[t]{6}{*}{$\mathrm{R}$ caudate/thalamus } & 106 & $17-2516$ & 5.943 & R precentral, BA 6 & 80 & $\begin{array}{lll}55 & -3 & 34\end{array}$ & 6.010 & $\begin{array}{l}\text { L inferior / superior } \\
\text { parietal, BA } 40 / 7\end{array}$ & 400 & $-51-3332$ & 9.736 \\
\hline & & & & R TPJ, BA 39 & 70 & $35-5926$ & 5.386 & $\begin{array}{l}\text { L OFC / insula / } \\
\text { precentral, BA 47/44 }\end{array}$ & 366 & -4123 & 6.376 \\
\hline & & & & & & & & $\begin{array}{l}\text { medial frontal, } \\
\text { BA } 6 \text { SMA }\end{array}$ & 143 & $1-1166$ & 7.994 \\
\hline & & & & & & & & $\begin{array}{l}\text { L middle temporal, } \\
\text { BA } 21 / 22\end{array}$ & 111 & $\begin{array}{ll}-45-31 & 4\end{array}$ & 6.340 \\
\hline & & & & & & & & $\mathrm{R}$ cerebellum, culmen & 97 & $\begin{array}{ll}7-51 & -8\end{array}$ & 7.829 \\
\hline & & & & & & & & R precuneus, BA 7 & 88 & $13-6350$ & 7.101 \\
\hline
\end{tabular}

\section{Non-Cancer Negative $>$ Non-Cancer Positive}

\section{$\mathrm{NC}$ - minus NC+}

\begin{tabular}{|c|c|c|c|c|c|c|c|c|c|c|c|}
\hline $\begin{array}{l}\text { L precuneus, posterior } 14 \\
\text { cingulate, } \mathrm{BA} 7 / 31\end{array}$ & & $-15-5128$ & -5.976 & $\begin{array}{l}\mathrm{L} \text { anterior cingulate, } \\
\text { middle frontal BA } 32\end{array}$ & 114 & -191334 & -5.176 & $\begin{array}{l}\mathrm{L} \text { middle temporal, } \\
\text { middle occipital, }\end{array}$ & 145 & $-49-6920$ & -6.696 \\
\hline \multirow[t]{3}{*}{ R cuneus, BA 18} & 83 & $5-7120$ & -5.073 & $\begin{array}{l}\mathrm{R} \text { anterior superior } \\
\text { temporal, BA } 38\end{array}$ & 91 & $7-20$ & -4.093 & BA $39 / 19$ & & & \\
\hline & & & & L OFC, BA 47 & 86 & $\begin{array}{lll}-2531 & 0\end{array}$ & -6.873 & & & & \\
\hline & & & & L middle frontal, BA 6 & 78 & $-21 \quad 544$ & -5.310 & & & & \\
\hline
\end{tabular}

Note. Activations were obtained using an independent voxel threshold of $p<01$ and a cluster threshold of 70 voxels $\left(560 \mathrm{~mm}^{3}\right)$, with a resampled voxel size of $2 \times 2 \times 2 \mathrm{~mm}$. Clusters larger than 125,123 , and 120 voxels for the meditators cancer survivors, and controls, respectively, are significant at $p<.05\left(984 \mathrm{~mm}^{3}, 1000 \mathrm{~mm}^{3}, 960 \mathrm{~mm}^{3}\right)$. Clusters were initially obtained from the contrasts indicated in the table using a random effects ANOVA for each participant group. Activation maps from the ANOVAs were then submitted to two conjunction analyses: one between meditators and controls; one between cancer survivors and controls. Because no clusters larger than 70 voxels where shared between the two participant groups in either conjunction analysis, no shared clusters are shown (see the text for descriptions of smaller shared fragments of larger clusters). Talairach coordinates are used to indicate the maximum intensity voxel in each cluster. BA is Brodmann area, OFC is orbitofrontal cortex, TPJ is temporal parietal junction, SMA is supplemental motor area. 
Table 3. Significant activations in contrasts between cancer and non-cancer phrases from two conjunction analyses (meditators vs. controls; cancer survivors vs. controls).

\begin{tabular}{|c|c|c|c|c|c|c|c|c|c|c|c|}
\hline \multicolumn{4}{|c|}{ Meditators } & \multicolumn{4}{|c|}{ Controls } & \multicolumn{4}{|c|}{ Cancer Survivors } \\
\hline brain region & $\begin{array}{l}\text { cluster } \\
\text { volume }\end{array}$ & \multicolumn{2}{|c|}{ max intensity voxel } & brain region & $\begin{array}{l}\text { cluster } \\
\text { volume }\end{array}$ & \multicolumn{2}{|c|}{ max intensity voxel } & brain region & $\begin{array}{l}\text { cluster } \\
\text { volume }\end{array}$ & \multicolumn{2}{|c|}{ max intensity voxel } \\
\hline & & & & $\begin{array}{l}\text { Cancer All } \\
(\mathrm{C}+\& \mathrm{C}-) \mathrm{m}\end{array}$ & $\begin{array}{l}>\text { Non } \\
\text { hinus }(\end{array}$ & $\begin{array}{l}\text {-Cancer } A \\
\mathrm{NC}+\& \mathrm{~N}(\end{array}$ & & & & & \\
\hline R precuneus, BA 7 & 117 & $5-3942$ & 7.236 & & & & & R precuneus, BA 7 & 183 & $9-6148$ & 5.475 \\
\hline \multirow[t]{2}{*}{$\begin{array}{l}\text { R superior frontal, } \\
\text { BA } 8\end{array}$} & 79 & 33554 & 4.528 & & & & & $\begin{array}{l}\text { L posterior cingulate, } \\
\text { BA } 23\end{array}$ & 87 & $-9-5320$ & 5.287 \\
\hline & & & & & & & & $\begin{array}{l}\text { R middle occipital, } \\
\text { BA } 19, \text { EBA }\end{array}$ & 84 & $41-67-6$ & 5.915 \\
\hline \multicolumn{12}{|c|}{$\begin{array}{l}\text { Non-Cancer } \text { All }>\text { Cancer All } \\
(\mathrm{NC}+\& \text { NC- }) \text { minus }(\mathrm{C}+\& \mathrm{C}-)\end{array}$} \\
\hline \multirow[t]{8}{*}{ L 1 PFC, BA 46} & 95 & -393718 & -5.408 & $\begin{array}{l}\text { bilateral precentral, } \\
\text { medial frontal } \\
\text { SMA, BA } 6\end{array}$ & 785 & $5-1160$ & -6.910 & & & & \\
\hline & & & & $\begin{array}{l}\text { L OFC, } \\
\text { anterior insula BA } 47\end{array}$ & 434 & $\begin{array}{lll}-35 & 27 & -4\end{array}$ & -8.717 & & & & \\
\hline & & & & $\begin{array}{l}\text { L posterior insula, } \\
\text { superior temporal, } \\
\text { BA 22/41 }\end{array}$ & 347 & $-59-13 \quad 4$ & -6.569 & & & & \\
\hline & & & & $\begin{array}{l}\text { L inferior parietal, } \\
\text { BA } 40\end{array}$ & 250 & $-47-4350$ & -6.505 & & & & \\
\hline & & & & $\begin{array}{l}\mathrm{R} \text { fusiform / } \\
\text { middle temporal, } \\
\text { BA20/21 }\end{array}$ & 181 & $45-25-14$ & -6.339 & & & & \\
\hline & & & & $\begin{array}{l}\text { R IFG / } \\
\text { anterior insula BA } 45\end{array}$ & 123 & $5517 \quad 0$ & -6.172 & & & & \\
\hline & & & & $\begin{array}{l}\text { L superior temporal, } \\
\text { BA } 22 / 21\end{array}$ & 77 & $-55-4910$ & -6.466 & & & & \\
\hline & & & & L precentral, BA 4 & 73 & $-47-946$ & -4.841 & & & & \\
\hline
\end{tabular}


Table 3 (continued)

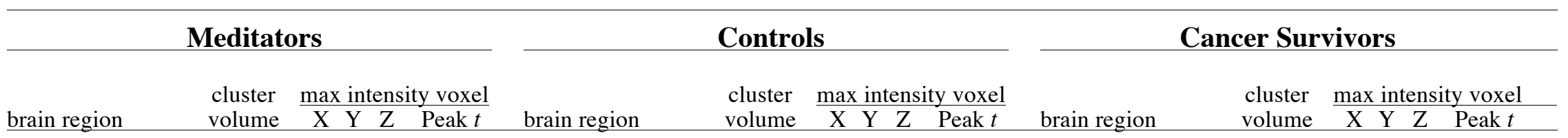

\section{Cancer Positive $>$ Non-Cancer Positive}

$\mathrm{C}+$ minus $\mathrm{NC}+$

\begin{tabular}{|c|c|c|c|}
\hline dmPFC, BA 8 & 311 & 32560 & 6.819 \\
\hline precuneus, BA 7 & 210 & $7-4544$ & 5.655 \\
\hline $\begin{array}{l}\text { R paracentral lobule, } \\
\text { posterior central, BA } 3\end{array}$ & 108 & $13-4362$ & 5.407 \\
\hline $\begin{array}{l}\text { middle cingulate, } \\
\text { BA } 23\end{array}$ & 103 & $3-23 \quad 32$ & 4.898 \\
\hline L cuneus, BA 19 & 79 & $-9-8124$ & 5.153 \\
\hline
\end{tabular}

$\begin{array}{lcrrr}\begin{array}{l}\text { R middle occipital, } \\ \text { BA 19/37 EBA }\end{array} & 139 & 49-63 & -4 & 7.125 \\ \begin{array}{l}\text { L precuneus, BA 7 } \\ \begin{array}{l}\text { R posterior cingulate / } \\ \text { cuneus, BA 30/18 }\end{array}\end{array} & 81 & -19-49 & 46 & 5.792 \\ \begin{array}{l}\text { L middle occipital, } \\ \text { BA 19/37 EBA }\end{array} & 80 & -43-63 & -4 & 9.193 \\ \begin{array}{l}\text { cuneus, BA 17/18 } \\ \text { R precuneus, BA 7 }\end{array} & 78 & 1-81 & 14 & 7.148 \\ & 73 & 25-65 & 32 & 7.196\end{array}$

\section{Non-Cancer Positive $>$ Cancer Positive} $\mathrm{NC}+$ minus $\mathrm{C}+$

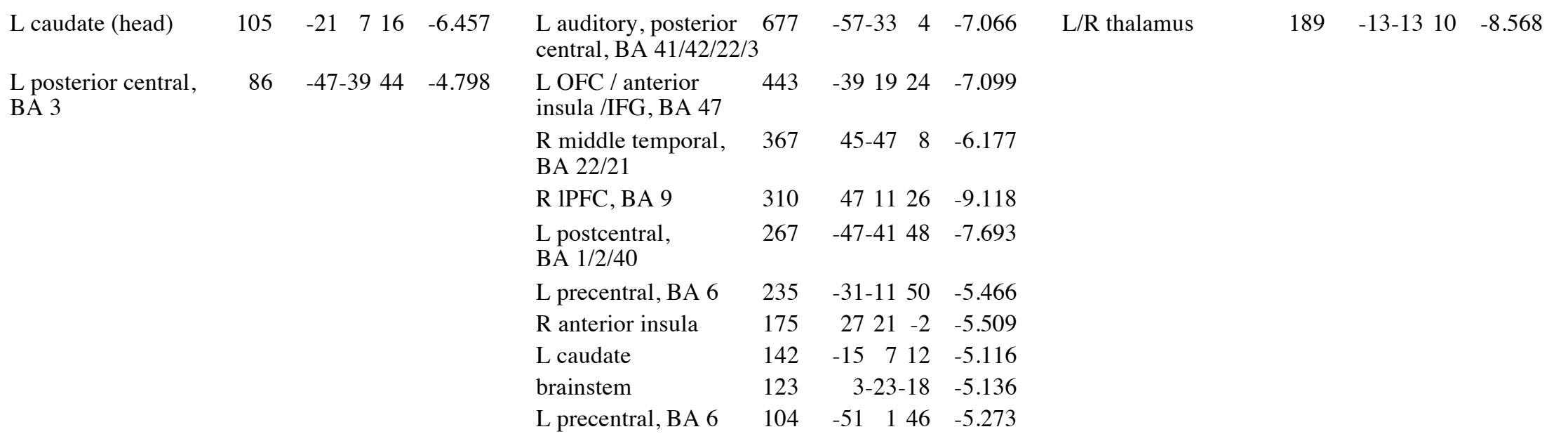




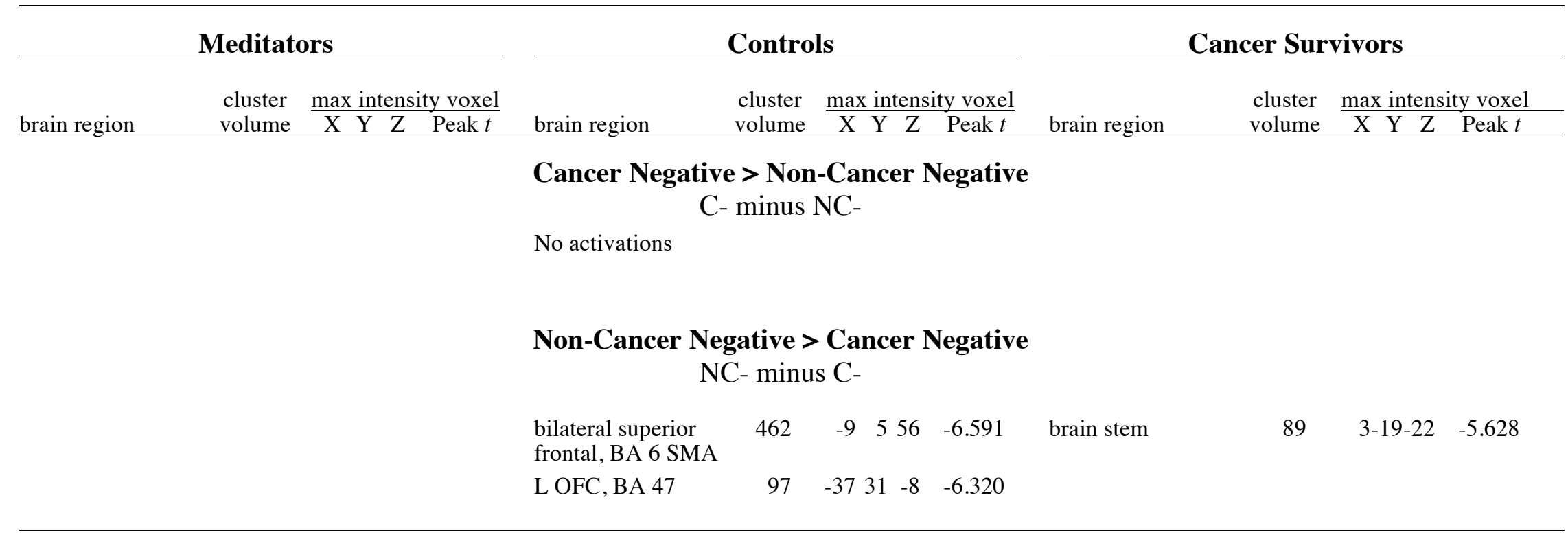

Note. Activations were obtained using an independent voxel threshold of $p<01$ and a cluster threshold of 70 voxels $\left(560 \mathrm{~mm}^{3}\right)$, with a resampled voxel size of $2 \times 2 \times 2 \mathrm{~mm}$. Clusters larger than 125, 123, and 120 voxels for the meditators cancer survivors, and controls, respectively, are significant at $p<.05\left(984 \mathrm{~mm}^{3}, 1000 \mathrm{~mm}^{3}, 960 \mathrm{~mm}^{3}\right)$. Clusters were initially obtained from the contrasts indicated in the table using a random effects ANOVA for each participant group. Activation maps from the ANOVAs were then submitted to two conjunction analyses: one between meditators and controls; one between cancer survivors and controls. Because no clusters larger than 70 voxels where shared between the two participant groups in either conjunction analysis, no shared clusters are shown (see the text for descriptions of smaller shared fragments of larger clusters). Talairach coordinates are used to indicate the maximum intensity voxel in each cluster. BA is Brodmann area, OFC is orbitofrontal cortex, SMA is supplemental motor area, EBA is extrastriate body area, IFG is inferior frontal gyrus, dmPFC is dorsomedial prefrontal cortex, IPFC is lateral prefrontal cortex. 
Matched Controls

All Negative $>$ All Positive (C1)

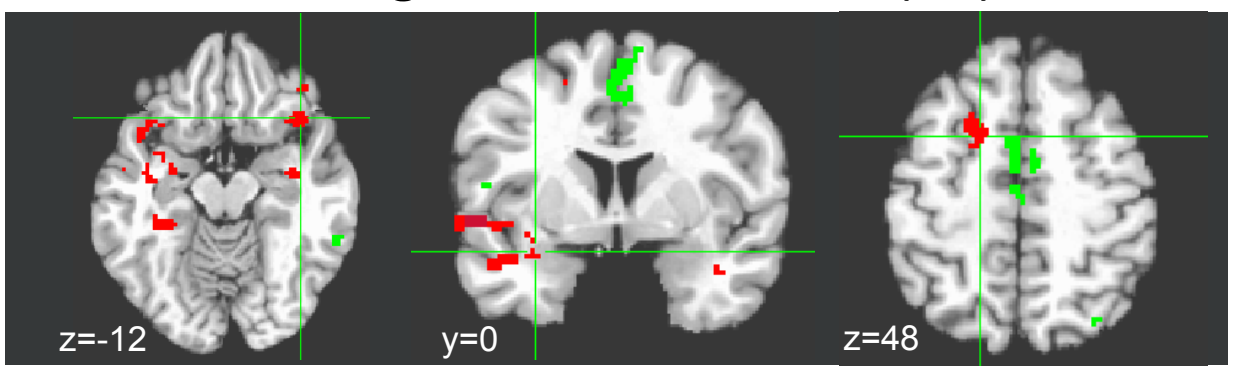

Cancer Positive $>$ Cancer Negative (C2)

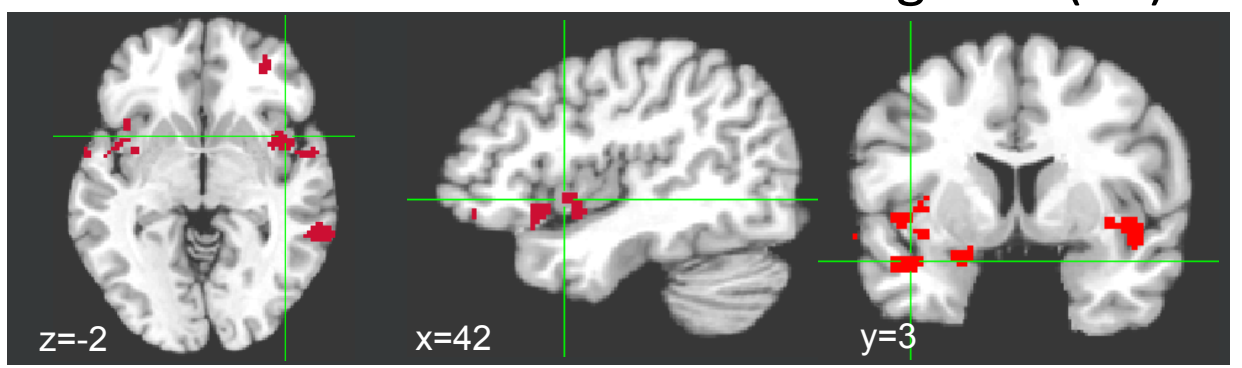

Cancer Survivors

All Positive $>$ All Negative (C1)

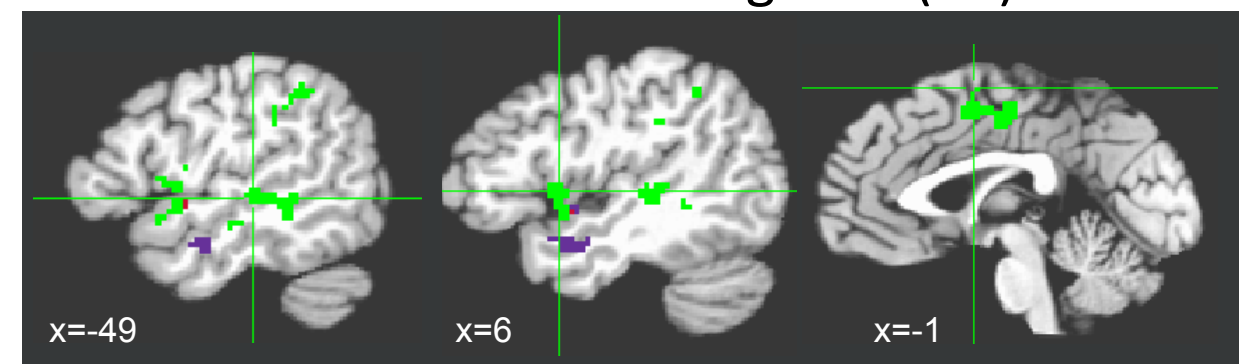

Non-Cancer Positive $>$ Non-Cancer Negative (C3)

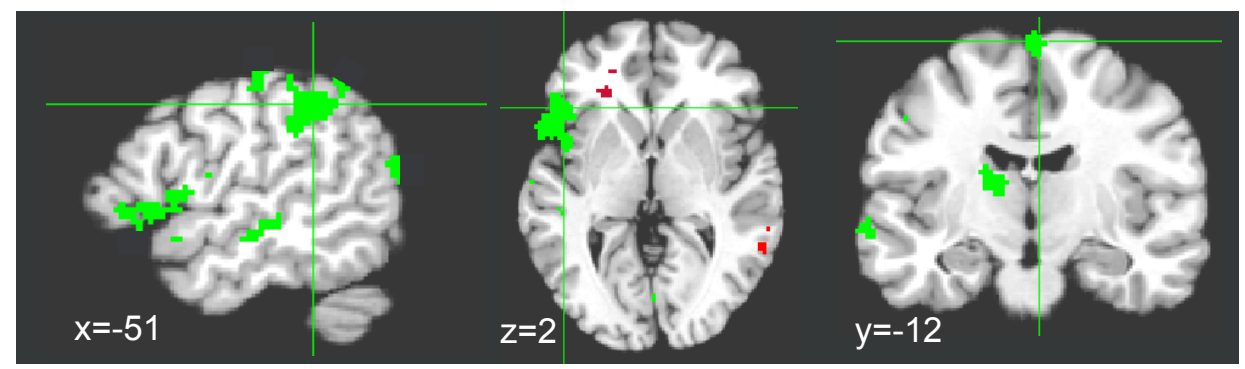




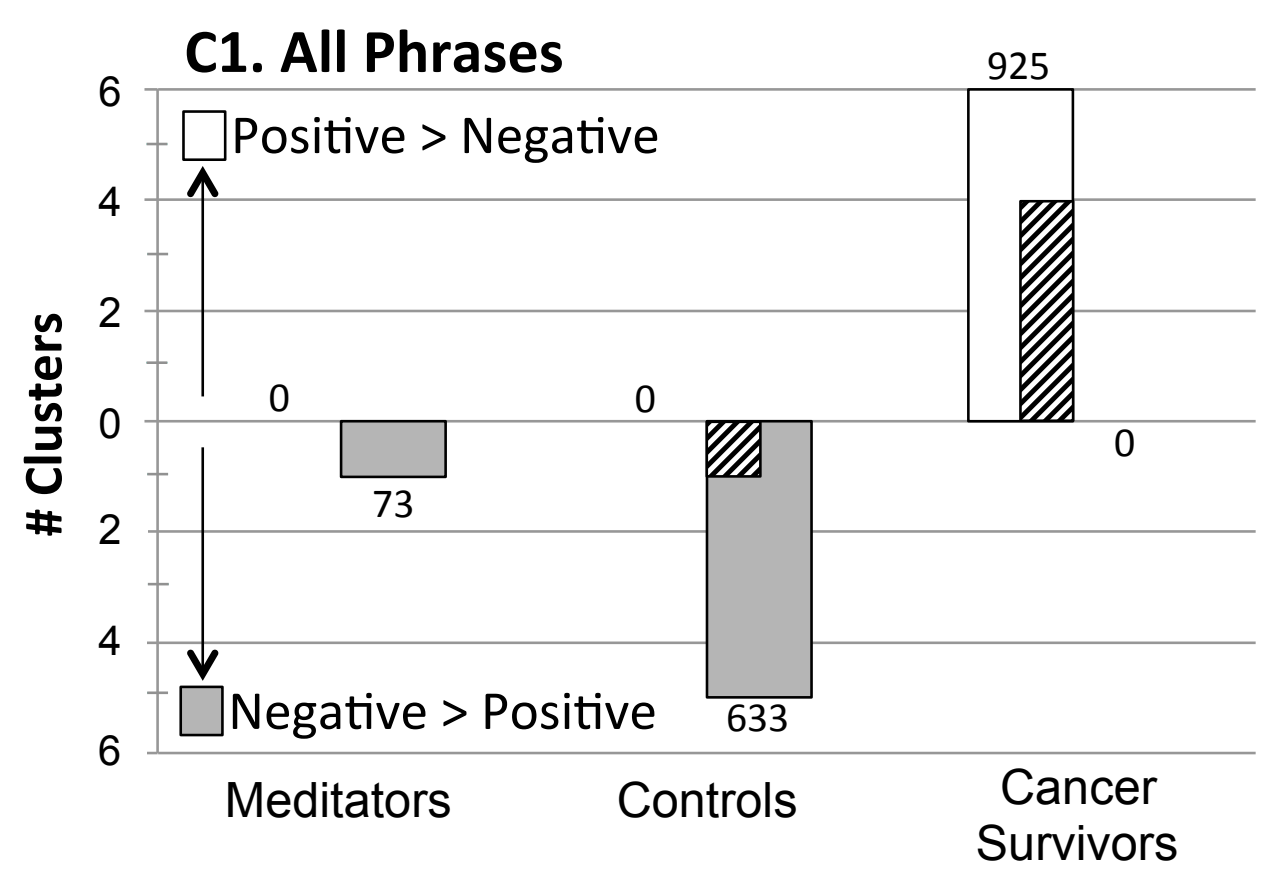

\section{Positive vs. Negative Phrases}

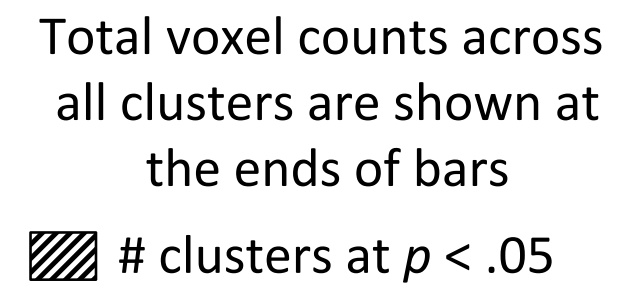

\section{C2. Cancer Phrases}
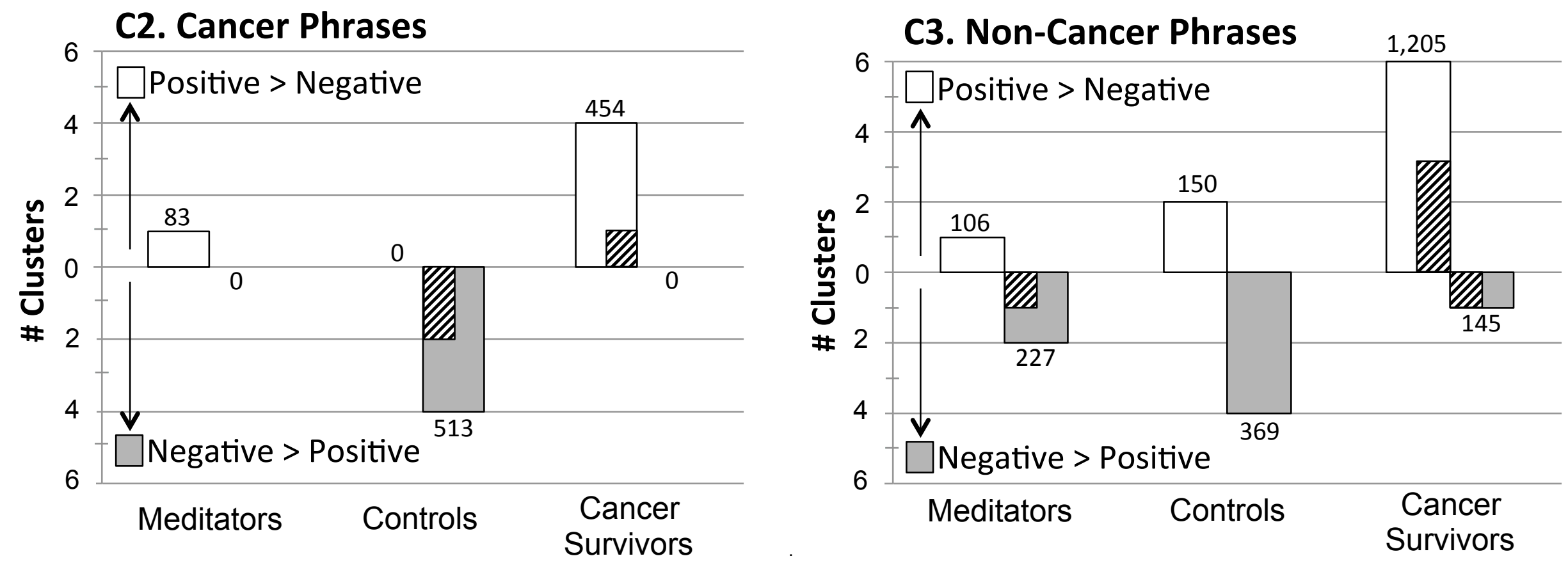
Matched Controls

Positive Non-Cancer >

Positive Cancer (C5)

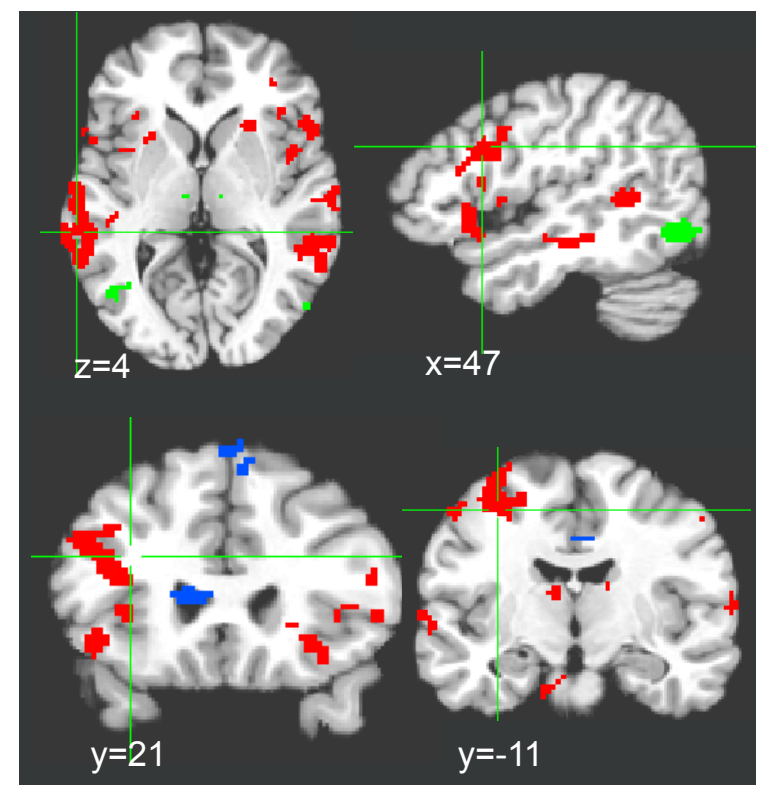

Experienced Meditators

Positive Cancer >

Positive Non-Cancer (C5)

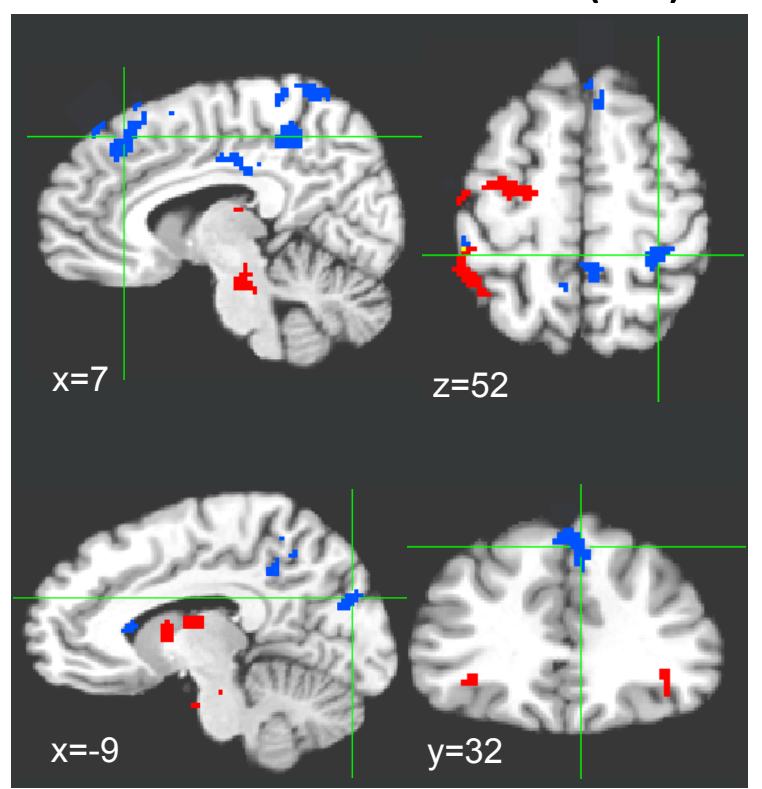

\section{Cancer Survivors}

Positive Cancer >

Positive Non-Cancer (C5)

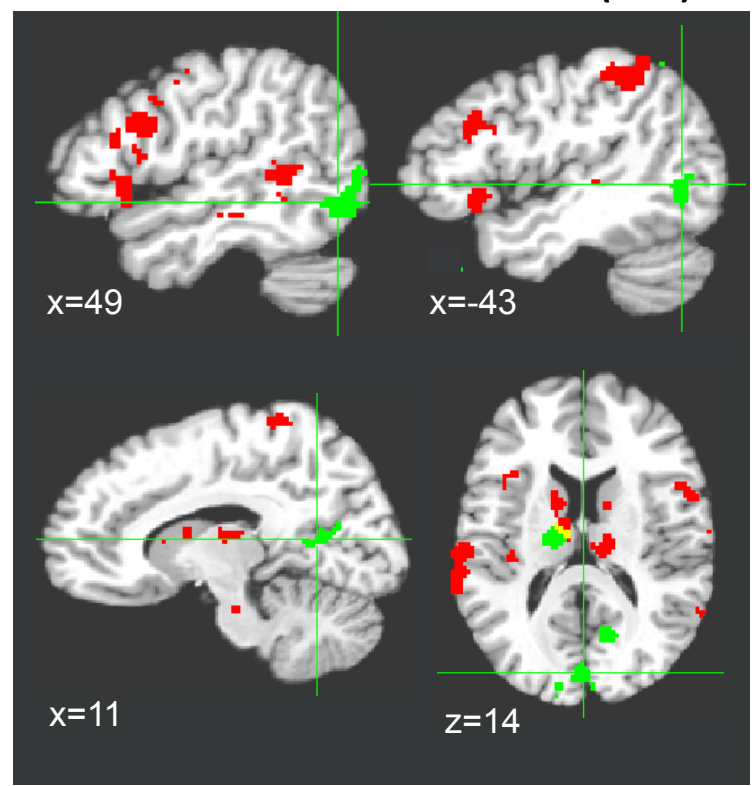


C4. All Phrases

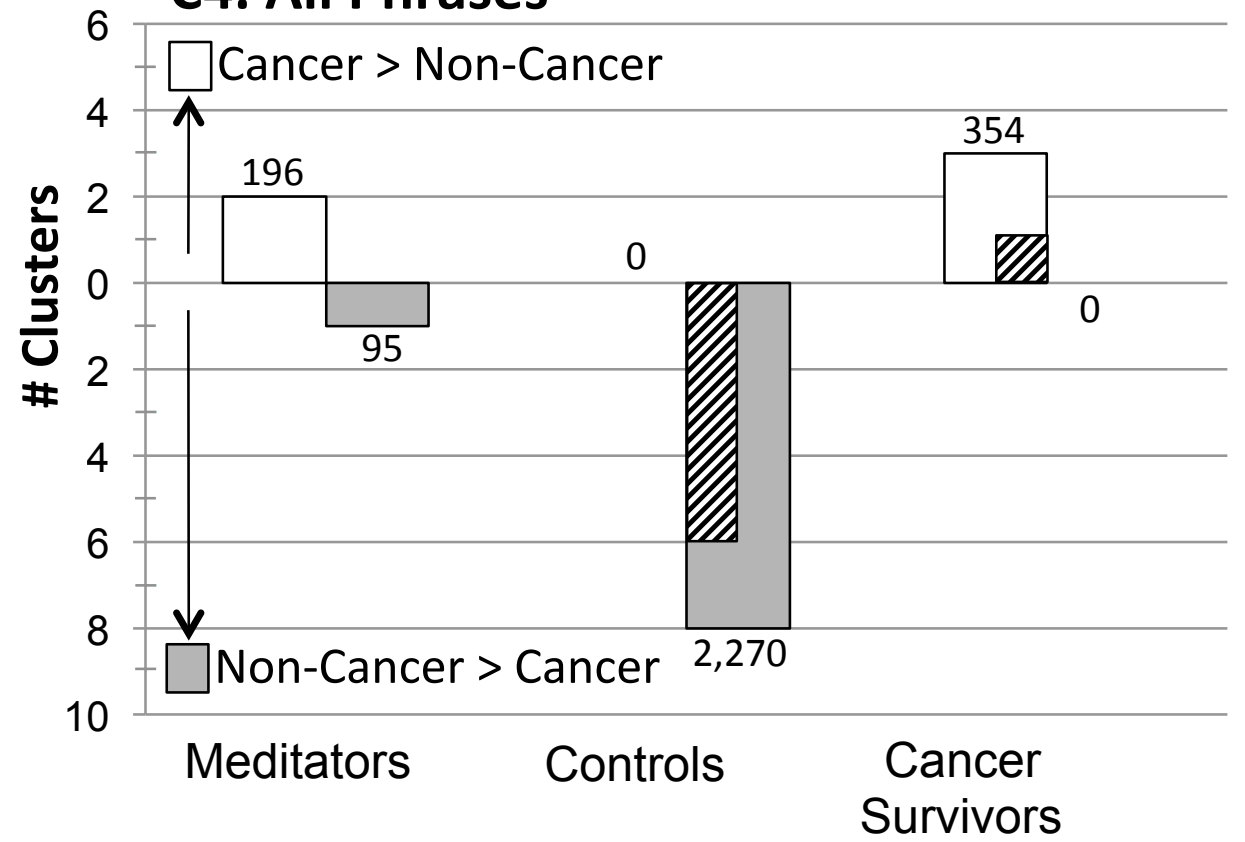

C5. Positive Emotion Phrases

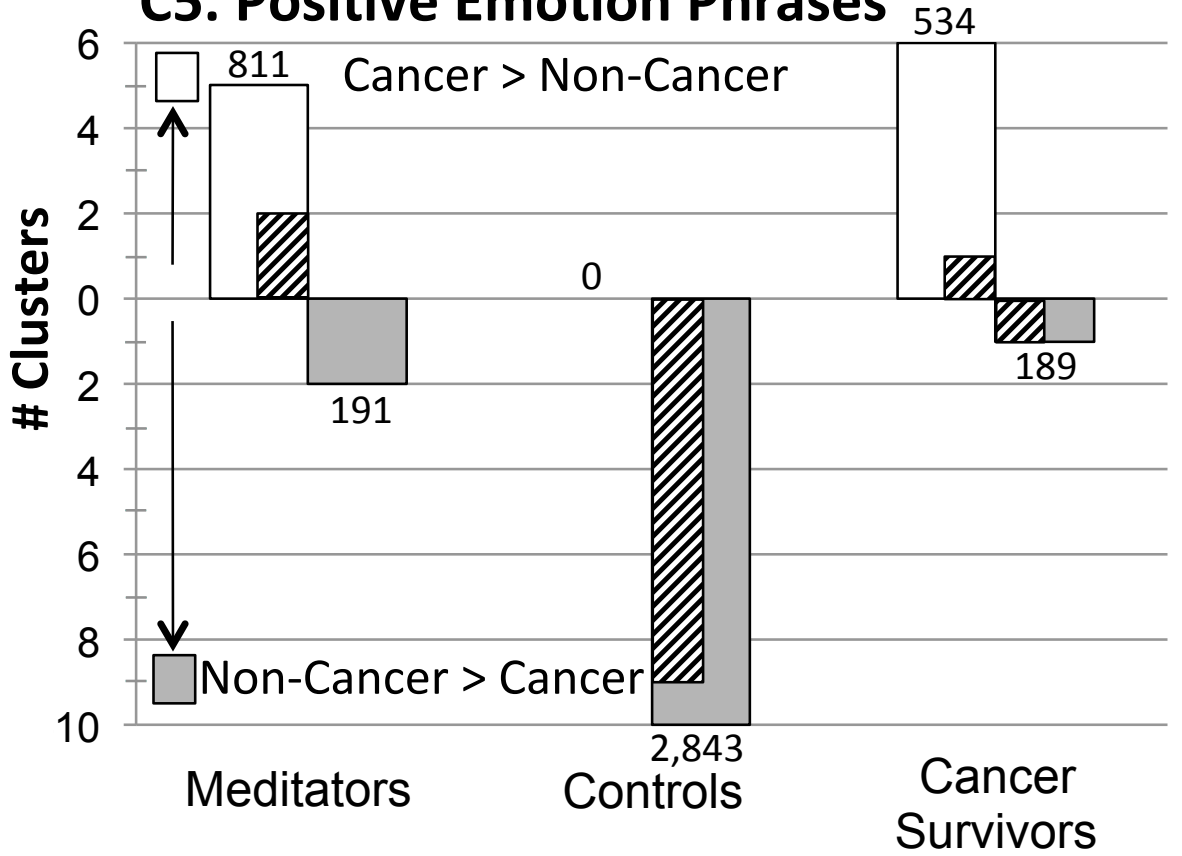

\section{Cancer vs. Non-Cancer Phrases}

\section{Total voxel counts across} all clusters are shown at the ends of bars

UIA \# clusters at $p<.05$

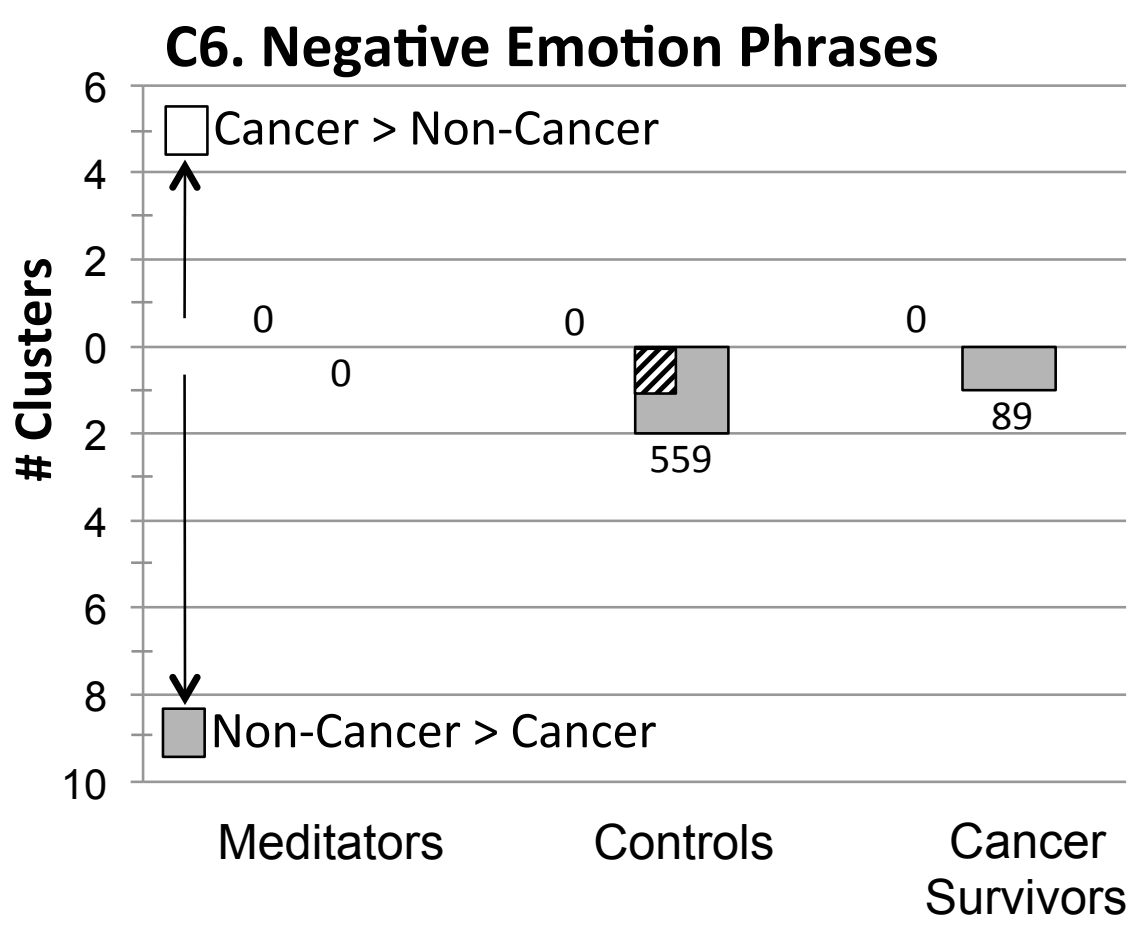




\section{Supplementary Materials}

\section{Differences in Emotional Responses Between Meditators, Cancer Survivors, and Controls}

Bauer-Wu, Butler, Rajendra, Whitworth, Pagnoni, Hasenkamp, Wilson-Mendenhall, Lebois, Drucker, Simmons, Dunne, Ozawa-de Silva, Barrett, and Barsalou

Table S1. Demographic and individual differences measures for the three participant groups.

\begin{tabular}{lcccc}
\hline & \multicolumn{3}{c}{ Participant group } \\
\cline { 2 - 3 } Measure & Meditators & Cancer survivors & Controls & Between group $p$ value \\
Age & $40.0 \pm 12.1$ & $44.1 \pm 10.5$ & $37.2 \pm 14.7$ & .46 \\
Gender (\% female) & 42.9 & 55.6 & 57.2 & $.72^{\mathrm{a}}$ \\
Education & $4.1 \pm 0.9$ & $4.0 \pm 0.7$ & $4.4 \pm 0.8$ & .54 \\
Pre-scan happiness & $2.3 \pm 1.8$ & $2.7 \pm 3.0$ & $2.5 \pm 1.8$ & .90 \\
Pre-scan tenseness & $2.04 \pm 1.3$ & $1.8 \pm 1.9$ & $1.9 \pm 1.0$ & .89 \\
PANAS-X positive affect & $37.9 \pm 7.7$ & $32.2 \pm 6.3$ & $34.5 \pm 5.0$ & .50 \\
PANAS-X negative affect & $15.2 \pm 4.9$ & $15.9 \pm 5.0$ & $13.9 \pm 2.7$ & $.03^{\mathrm{b}}$ \\
Total CSoSI stress symptoms & $20.3 \pm 16.0$ & $38.6 \pm 16.3$ & $21.0 \pm 18.3$ & \\
\hline
\end{tabular}

Notes. Values are averages \pm 1 standard deviation. For education, 2 represented a high school education, 3 , represented some college, 4 represented a college degree, and 5 represented an advanced degree. The two pre-scan measures each assessed tenseness and happiness on a continuous 1-7 visual analogue scale. PANAS-X is the expanded version of Positive and Negative Affect Schedule. CSoSI is the Calgary Symptoms of Stress Inventory.

a Chi Square test

b Tukey post hoc tests: cancer survivors $>$ meditators ( $p=.043)$; cancer survivors $>$ controls $(p=.054)$ 
Table S2. Average ratings, average phrase length, and proportion of the final phrase word for the 5 sets of stimulus phrases.

\begin{tabular}{|c|c|c|c|c|c|c|c|c|c|}
\hline \multirow[b]{2}{*}{ Phrase type } & \multirow[b]{2}{*}{$\mathrm{N}$} & \multicolumn{3}{|c|}{ Ratings } & \multicolumn{2}{|c|}{ Phrase Length } & \multicolumn{3}{|c|}{ Final Phrase Word } \\
\hline & & Affect & Familiarity & Cancer Relevance & \# Words & \# Syllables & Noun & Verb & Modifier \\
\hline $\mathrm{NC}+$ & 45 & 6.12 & 5.74 & 2.95 & 2.38 & 4.73 & .84 & .04 & .11 \\
\hline NC- & 45 & 1.77 & 2.91 & 1.85 & 2.18 & 4.53 & .96 & .02 & .02 \\
\hline $\mathrm{C}+$ & 45 & 6.34 & 5.91 & 5.70 & 2.31 & 4.51 & .84 & .07 & .09 \\
\hline C- & 45 & 1.54 & 4.58 & 6.12 & 2.31 & 4.38 & .89 & .04 & .07 \\
\hline Neut & 90 & 4.18 & 4.82 & 2.42 & 2.38 & 4.33 & .94 & .01 & .04 \\
\hline
\end{tabular}

Notes. NC is not-related to cancer, and C is related to cancer. + is positively valenced affect, - is negatively valenced affect, and neut is neutrally valenced affect. $\mathrm{N}$ is the number of phrases of each type. Affect was assessed on a scale that ranged from 1 (highly negative) to 4 (neutral) to 7 (highly positive). Familiarity was assessed on a scale that ranged from 1 (completely unfamiliar) to 7 (highly familiar). Cancer relevance was assessed on a scale that ranged from 1 (completely unrelated to cancer) to 4 (equally related to cancer and other things) to 7 (only related to cancer).

Table S3. Proportion of phrases containing each type of phrase content.

\begin{tabular}{|c|c|c|c|c|c|c|c|c|}
\hline \multirow[b]{2}{*}{ Type } & \multicolumn{8}{|c|}{ Phrase content } \\
\hline & Bodily states & Mental life & Life activities & Significant others & Future events & Disease & Treatment & Medical events \\
\hline $\mathrm{NC}+$ & .07 & .33 & .33 & .18 & .04 & .00 & .02 & .02 \\
\hline NC- & .07 & .13 & .20 & .33 & .00 & .13 & .00 & .13 \\
\hline $\mathrm{C}+$ & .11 & .22 & .09 & .07 & .11 & .13 & .16 & .11 \\
\hline C- & .24 & .11 & .04 & .04 & .07 & .20 & .18 & .11 \\
\hline Neut & .27 & .14 & .16 & .13 & .04 & .06 & .12 & .08 \\
\hline
\end{tabular}

Notes. NC is not-related to cancer, and C is related to cancer. + is positively valenced affect, - is negatively valenced affect, and neut is neutrally valenced affect. 


\section{Image Acquisition and Analysis Details}

Image acquisition. The neuroimaging data were collected in the Biomedical Imaging Technology Center at Emory University (BITC) on a research-dedicated 3T Siemens Trio scanner. In each functional run, 210 T2* weighted echo planar image volumes depicting BOLD contrast were collected using a Siemens 12-channel head coil and parallel imaging with an iPAT acceleration factor of 2 . Each volume was collected using a scan sequence that had the following parameters: 56 contiguous $2 \mathrm{~mm}$ slices in the axial plane, interleaved slice acquisition, $\mathrm{TR}=3000 \mathrm{~ms}, \mathrm{TE}=30 \mathrm{~ms}$, flip angle $=90^{\circ}$, bandwidth $=2442 \mathrm{~Hz} / \mathrm{Px}, \mathrm{FOV}=220 \mathrm{~mm}$, matrix $=64$, voxel size $=3.44 \mathrm{~mm} \times 3.44 \mathrm{~mm} \times 2 \mathrm{~mm}$. This scanning sequence was selected after testing a variety of sequences for susceptibility artifacts in orbitofrontal cortex, the temporal poles, and medial temporal cortex. We selected this sequence, not only because it minimized susceptibility artifacts by using thin slices and parallel imaging, but also because using $3.44 \mathrm{~mm}$ in the X-Y dimensions yielded a voxel volume large enough to produce a satisfactory temporal signal-to-noise ratio.

In each of the two anatomical runs, a T1 weighted volume was collected using a high resolution MPRAGE scan sequence that had the following parameters: 192 contiguous slices in the sagittal plane, singleshot acquisition, $\mathrm{TR}=2300 \mathrm{~ms}, \mathrm{TE}=4 \mathrm{~ms}$, flip angle $=8^{\circ}, \mathrm{FOV}=256 \mathrm{~mm}$, matrix $=256$, bandwidth $=130 \mathrm{~Hz} / \mathrm{Px}$, voxel size $=1 \mathrm{~mm} \times 1 \mathrm{~mm} \times 1 \mathrm{~mm}$.

Image preprocessing and analysis. All preprocessing and statistical analyses were conducted in AFNI (Cox, 1996). The first anatomical scan was registered to the second, and the two datasets averaged to produce a single high-quality anatomical volume. Initial preprocessing steps of the functional data included slice time correction and motion correction in which all volumes were registered spatially to a volume within the last functional run. A volume in the last run was selected as the registration base because it was collected closest in time to the second anatomical scan, which facilitated later alignment of the functional and anatomical data. The functional data were smoothed using an isotropic $6 \mathrm{~mm}$ full-width half-maximum Gaussian kernel. Voxels outside the brain were removed from further analysis, as were high-variability low-intensity voxels likely to be shifting in and out of the brain due to minor head motion. Finally, the signal intensities in each volume were divided by the mean signal value for the respective run and multiplied by 100 to produce percent signal change from the run mean. All later analyses were performed on these percent signal change data.

The averaged anatomical scan was corrected for non-uniformity in image intensity, skull-stripped, and then aligned with the functional data.
The resulting aligned anatomical dataset was warped to Talairach space using an automated procedure employing the TT_N27 template.

Regression analysis was performed at the individual level using a canonical, fixed-shape Gamma function to model the hemodynamic response. Betas were calculated from event onsets for the 5 critical conditions (NC+, NC-, C+, C-, and Neut). Six regressors obtained from volume registration during preprocessing were included to remove any residual signal changes correlated with movement (translation in the $X$, $\mathrm{Y}$, and $\mathrm{Z}$ planes; rotation around the $\mathrm{X}, \mathrm{Y}$, and $\mathrm{Z}$ axes). Scanner drift was removed by finding the best-fitting polynomial function correlated with time in the preprocessed time course data.

The betas for the 5 critical conditions from each participant's regression were warped to Talairach space in preparation for group analyses. Each participant's betas were then submitted to a repeatedmeasures one-way ANOVA at the group level for the respective group (i.e., one ANOVA each for the cancer survivors, meditators, and controls). Significant activations were established using a voxel-wise significance level of $p<.01$ and a cluster threshold that yielded a whole brain significance level of $p<.05$ corrected for multiple comparisons $(125,123$, and 120 resampled voxels for the cancer survivors, meditators, and controls, respectively; $1000,984,960 \mathrm{~mm}^{3}$,). To provide further detail on brain activations, clusters down to 70 voxels are reported $\left(540 \mathrm{~mm}^{3}\right)$. Many of the additional activations observed at the lower threshold fell in areas important for emotion (Kober et al., 2008; Lindquist, Wager, Kober, Bliss-Moreau, \& Barrett, 2012). Furthermore, the overall pattern of results became stronger at the lower threshold, as described in the main text. The spatial extent threshold was established using Alphasim in AFNI, which runs Monte Carlo simulations to estimate extent thresholds needed to exceed cluster sizes of false positives at a given voxel-wise threshold.

Within each of the three groups, linear contrasts were computed to test the hypotheses of interest. One set of three contrasts assessed differences in activations for positive vs. negative phrases:

(C1) all positive phrases - all negative phrases, (NC+ \& $\mathrm{C}+$ ) - (NC- \& C-)

(C2) positive non-cancer phrases - negative non-cancer phrases, NC+ - NC-

(C3) positive cancer phrases - negative cancer phrases, C+ - C-

Another set three contrasts assessed differences in activations for cancerrelated vs. non-cancer related phrases.

(C4) all cancer phrases - all non-cancer phrases, (C+ \& C- $)-(\mathrm{NC}+\& \mathrm{NC}-)$

(C5) positive cancer phrases - positive non-cancer phrases, $\mathrm{C}+-\mathrm{NC}+$

(C6) negative cancer phrases - negative non-cancer phrases, $\mathrm{C}$ - - NCFor each contrast, conjunction analyses were performed to test the hypotheses that the different participant groups produced different 
emotional responses to the same emotional stimuli. Specifically, the conjunction of the significant activations for the cancer survivors vs. the controls was computed. In the second analysis, the conjunction of the significant activations for the meditators vs. the controls was computed.

In each conjunction analysis, three types of voxels were identified: (1) voxels active only in the cancer survivor (meditator) group, (2) voxels active only in the control group, and (3) voxels active in both the cancer survivor (meditator) and control groups. When a significant cluster was divided into parts that occurred, first, as a unique part for one group, and second, as a shared part for both groups, clusters could become smaller than the original cluster threshold. When small fragments of a cluster were from the same brain area as larger fragments, all these fragments were combined into a single cluster to simplify presentation of the results. 


\section{References}

Cox, R. W. (1996). AFNI: software for analysis and visualization of functional magnetic resonance neuroimages. Computers and Biomedical research, 29(3), 162-173.

Kober, H., Barrett, L. F., Joseph, J., Bliss-Moreau, E., Lindquist, K., \& Wager, T. D. (2008). Functional grouping and cortical-subcortical interactions in emotion: A meta-analysis of neuroimaging studies. NeuroImage, 42(2), 998-1031.

doi:10.1016/j.neuroimage.2008.03.059

Lindquist, K. A., Wager, T. D., Kober, H., Bliss-Moreau, E., \& Barrett, L. F. (2012). The brain basis of emotion: A meta-analytic review.

Behavioral and Brain Sciences, 35(03), 121-143.

doi:10.1017/S0140525X11000446 